\title{
La formación y evolución del paisaje suburbano en época islámica: un ejemplo en el arrabal occidental de la capital omeya de Al-Andalus (Córdoba)
}

\author{
Formation and evolution of the suburban landscape in islamic times: an \\ example from the western suburbs of the umayyad capital of Al-Andalus \\ (Córdoba) \\ Rafael Clapés Salmoral * \\ Recibido: 29/04/2019 - Enviado a Evaluación: 20/05/2019 - Aprobado: 15/07/2019
}

\begin{abstract}
RESUMEN
En el presente trabajo abordamos el proceso de ocupación del perímetro suburbano de Madinat Qurțuba a través de un caso concreto, emplazado en el sector occidental de la ciudad. Se trata de un ejemplo que muestra cómo las primeras construcciones que tienen lugar durante época emiral, con una evidente labor islamizadora, influyeron en el urbanismo de los arrabales que se implantaron posteriormente durante el califato. Analizamos las edificaciones previas a la gran expansión del s. X y la evolución del urbanismo de este sector hasta su abandono definitivo como consecuencia de la fitna.
\end{abstract}

Palabras clave: Urbanismo, emiral, califal, arrabal, vivienda.

\section{INTRODUCCIÓN}

El estudio de las áreas suburbanas de la ciudad de Córdoba en época islámica ha sido un tema sumamente tratado por la producción bibliográfica de las últimas décadas. Las numerosas excavaciones desarrolladas en el entorno de la ciudad han generado una amplia documentación sobre el cinturón de arrabales construidos alrededor del recinto amurallado de la medina. El análisis macroespacial de esta vasta superficie exhumada ha permitido determinar la configuración de estos barrios extramuros, ordenados mediante calles de trazado ortogonal que delimitaban manzanas

\begin{abstract}
This work addresses the occupation proccess of the suburban perimeter of Madinat Qurtuba through a specific case, located in the western sector of the city. Within this area, the earliest constructions built during emiral times, which had an evident Islamizing intention, influenced the suburban urbanism developed during the caliphate. Our paper also aims to analyze the structures previous to the great caliphal expansion of the 10th c., and the urban evolution of this sector until its definitive abandonment as a consequence of the fitna.
\end{abstract}

Key words: urbanism, emiral, caliphal, suburban neighbourhood, domestic spaces.

regulares. Estas manzanas se encontraban ocupadas fundamentalmente por viviendas, pero también por otros elementos necesarios para su funcionamiento autónomo, como baños, mezquitas, edificios comerciales, instalaciones industriales o cementerios. Desde el punto de vista arqueológico, este análisis se ha centrado en el urbanismo resultante de la expansión que tuvo lugar a partir de la proclamación del califato por parte de 'Abd alRahmān III en el año 929. En las áreas excavadas la ocupación del terreno ha sido desigual, ya que hay zonas de arrabal muy densamente urbanizadas, con sucesivas fases de reforma, y otras que tuvieron un periodo de vida más

*Arqueólogo. 
corto y que apenas sufrieron transformaciones.

No obstante, aún quedan cuestiones por resolver sobre el periodo que comprende desde los años treinta del $\mathrm{s}$. X hasta los primeros del $\mathrm{s}$. $\mathrm{XI}$, momento en que se inicia la fitna. Estos interrogantes se relacionan con la identificación de sectores o construcciones que no tienen una función específicamente doméstica, y que podrían aportar más información sobre el funcionamiento general de estos arrabales. A este respecto, contamos con algunos trabajos que estudian estos elementos no específicamente domésticos de forma aislada, si bien, no hay todavía un análisis de conjunto, debido a que aún resta mucha documentación arqueológica por procesar y estudiar.

La ingente cantidad de información arqueológica con la que contamos para época califal contrasta con la escasez de datos obtenidos que puedan relacionarse con el paisaje previo y con el proceso de formación de este tejido urbano extramuros en época emiral. Este tema ha sido abordado en varias publicaciones (ACIÉN y VALLEJO, 1998; MURILLO; FUERTES y LUNA, 1999; MURILLO; CASAL y CASTRO, 2004; MURILLO, 2013), pero los testimonios aportados por las fuentes escritas solo han podido ser contrastados arqueológicamente de forma muy somera, especialmente si tomamos en consideración la gran cantidad de metros cuadrados excavados de estos arrabales. Las causas de esta disparidad tienen que ver, fundamentalmente, con la identificación de estas construcciones previas, ya que en muchos casos las intervenciones arqueológicas de urgencia imposibilitan actuar en estos solares con el tiempo necesario para detectar estas estructuras, que quedaron fagocitadas y transformadas por el arrabal califal que se asentó directamente sobre ellas. Afortunadamente, la identificación tanto de las técnicas constructivas (LEÓN, 2006; 2018b) como de los contextos cerámicos asociados a estas primeras ocupaciones suburbanas (CASAL et alii, 2005; SALINAS, 2013), han propiciado que en los últimos años se hayan registrado más ejemplos de construcciones de diversa envergadura anteriores a la eclosión urbanística del s. X.

La ocupación del espacio periurbano de Madinat Qurțba fue progresiva, así como fundamental, en el desarrollo de la labor islamizadora llevada a cabo en la ciudad a partir del acceso al poder de la dinastía Omeya (MURILLO et alii, 2010: p. 530). A grandes rasgos, para un primer momento - s. VIII- se ha constatado una continuidad entre elementos significativos de época tardoantigua y las primeras construcciones emirales ${ }^{2}$, que tuvieron en muchos casos su origen en grandes propiedades, antiguos vicus o centros de culto cristianos. En este paisaje extramuros se construyeron una serie de almunias asociadas a las élites cordobesas que, junto con los caminos, se constituyeron como núcleos esenciales en torno a los que se comenzó a general el tejido urbano posterior. El ejemplo más significativo, tanto por ser el primero como porque sirvió de modelo para las posteriores, fue la almunia de al-Rușāfa, construida por el emir 'Abd al-Rahmān I (MURILLO, 2009; MURILLO; LEÓN Y LÓPEZ, 2018). A partir de la primera mitad del s. IX se fundarían, por parte de la familia Omeya y de la aristocracia árabe, los edificios necesarios que debían dar servicio a cada nuevo barrio - mezquitas, baños o cementerios- - y que permitieron la continuación de la política islamizadora del gobierno. Esta primera organización del espacio periurbano, acaecida bajo el mandato de 'Abd al-Rahmān II, fue el punto de partida sobre el que se extendió la red de arrabales que germinó una vez instaurado el califato (MURILLO et alii 2010: pp. 535-536).

El arrabal meridional es un ejemplo excepcional de la primera ocupación del entorno de la medina (CASAL, 2008). Sin embargo, su destrucción por parte del emir al-Hakam I en el año 818 , y la prohibición de volver a construir en ese emplazamiento, impidió la evolución de su urbanismo hasta época califal. Al noroeste, los orígenes emirales del arrabal de Cercadilla solo estaban representados por algunas

2. Como ocurre con los grandes sistemas hidráulicos (MURILLO et alii, 2014). 
estructuras y por la identificación de un camino, testimonios que no permiten establecer las características generales del barrio (CASTRO, 2010: p. 615). En la zona suroccidental, las intervenciones llevadas a cabo en el recinto del Zoológico municipal permitieron documentar el uso de este sector desde, al menos, finales del s. VIII, que se prolongó hasta la fitna en el s. XI. Aunque se trató del primer caso para Córdoba donde se pudo apreciar una continuidad de uso desde época emiral temprana hasta el final del califato, las características de la actuación, mediante sondeos arqueológicos, no permitieron interpretar la funcionalidad de las estructuras (RUIZ et alii, 2008). En otros puntos de este sector oeste se han detectado también estas fases previas, como en la intervención llevada a cabo en el Fontanar. Aquí se excavó una almunia con grandes patios, cuya fundación tuvo lugar en el s. IX, que progresivamente acabó rodeada por un cementerio y un arrabal (MURILLO; CASAL y CASTRO, 2004: p. 267).

Este breve recorrido nos permite apreciar cómo poco a poco se va constatando arqueológicamente el proceso de ordenación del espacio extramuros desde época emiral, y su posterior transformación en las grandes superficies de arrabal que surgieron durante el califato. Con todo, nuestro conocimiento al respecto es aún muy exiguo, ya que carecemos de excavaciones lo suficientemente extensas con las que pueda documentarse este fenómeno evolutivo y, por tanto, que permitan estudiarlo y comprenderlo con mayor profundidad. A este respecto, presentamos a continuación un ejemplo documentado en el suburbio occidental, a través del cual se ha podido determinar cómo una edificación de época emiral condicionó e influyó en el trazado del arrabal califal posterior y, cómo a su vez este borró toda huella de esa construcción previa, que quedó materialmente engullida por el nuevo crecimiento urbano.

\section{EL CONTEXTO DEL HALLAZGO EN EL ARRABAL OCCIDENTAL}

El presente trabajo recoge los resultados obtenidos durante la excavación arqueológica llevada a cabo en un solar situado en el Plan Parcial $0-7^{3}$, que se desarrolló en gran medida durante la década pasada y que quedó inconcluso a consecuencia de la crisis económica que tuvo lugar en ese periodo. Desde hace unos años, la urbanización de sus parcelas se ha reactivado y actualmente se encuentra excavado casi en su totalidad. Esta gran superficie, de casi 36 hectáreas, es esencial para el estudio de los arrabales andalusíes, no solo por su extensión, sino también por la alta densidad y calidad de sus restos (Fig. 1). Se emplaza en un área donde la ocupación en época califal fue muy intensa, a lo que contribuyó, sin duda, la presencia de una antigua calzada en uso desde época romana. Nos referimos al Camino viejo de Almodóvar, que en época islámica vendría a coincidir con la vía que conectaba Qurtuba e Išbilliya por la margen norte del Río Guadalquivir ${ }^{4}$ Otro factor que incide en la importancia arqueológica de esta zona es que, tras la fitna de principios del s. $\mathrm{XI}$, estos terrenos recibieron un uso fundamentalmente agrícola que, en líneas generales, ha permitido la conservación de su trama islámica hasta la actualidad.

Pese a que hasta el momento no se ha realizado un estudio de conjunto de todas las excavaciones efectuadas en este sector ${ }^{5}$, se puede ya observar una serie de caminos y vías principales que ordenan todos los elementos urbanos de la zona. Grosso modo, esta área contó con una zona al sur ocupada por uno de los

\footnotetext{
3. El plan parcial se encuentra delimitado al norte por la Carretera de Palma del Rio, al oeste por la Ronda de Poniente, al este por la C/ Escritor Conde de Zamora y al sur por la Avda. del Aeropuerto.

4. Esta vía parte desde la Bab 'Amir, actual Puerta de Gallegos, ubicada en el lienzo oeste de la muralla de la ciudad. Se la ha identificado con la calzada romana Corduba-Hispalis (MELCHOR, 1995: pp. 129-133). En origen se trataba de una vía secundaria, que permaneció así hasta los inicios del califato, cuando adquirió mayor importancia por la expansión urbanística del área occidental (BERMúDEZ, 1993: p. 274)

5. Se han publicado tan solo algunos artículos sobre temas muy específicos referidos al Plan Parcial O-7 (CLAPÉS, 2013; CLAPÉS 20142015; LEÓN y CASAL, 2010: pp. 665-666; VÁZQUEZ, 2013: pp. 35-41).
} 


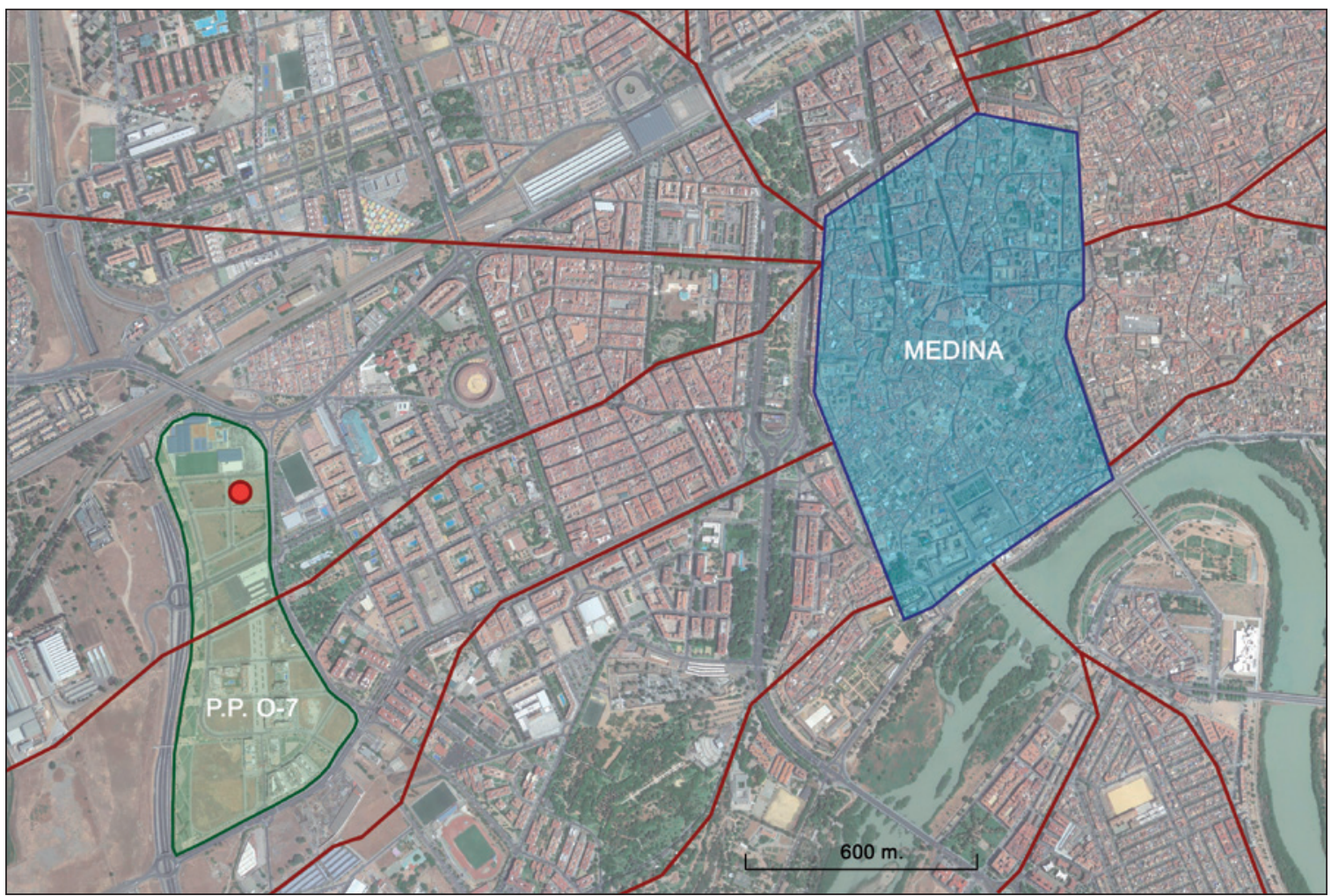

1. Localización de la parcela en el Plan Parcial O-7, al oeste del recinto amurallado.

cementerios más extensos y con más densidad de la ciudad en época medieval; con una zona central que albergó algunas propiedades de gran envergadura, con espacios agropecuarios y rodeadas de un parcelario que ha sufrido varias transformaciones; y con una zona al norte que experimentó un menor grado de transformación urbanística.

Este sector nos ofrece una magnifica imagen del arrabal occidental congelada en el momento de su abandono, en la que se aprecian las calles, las viviendas y otra serie de edificios que conformaron el barrio 6 . A pesar de que los elementos de época califal son los más abundantes por motivos evidentes, se han excavado en varias parcelas construcciones asociadas a época emiral, que nos remiten a la primera ocupación que tuvo lugar en todo este sector en el periodo islámico. En la mayoría de los casos se trata de diversas cimentaciones detecta- das de forma aislada en varios de estos solares, caracterizadas por un alto grado de arrasamiento y amortizadas por las estructuras califales (CRIADO, 2007; RODRÍGUEZ, 2008; CEPILLO y BAREA, 2017: p. 1282). En otras parcelas solo se han encontrado algunos pozos asociados a este primer momento emiral (LIÉBANA, 2008). En los solares donde se hallaron áreas algo más extensas sin urbanizar, se documentaron una serie de espacios constructivos en los que esta fase inicial se percibe de forma más clara. Nos referimos, por ejemplo, a una construcción con potentes cimientos a la que se añadieron nuevos edificios en época califal, que alternaban con zonas abiertas que apuntan a un uso agropecuario de este sector (MOLINA, 2007). Cerca del ejemplo anterior se ubicó otro solar que contaba con un espacio ajardinado de grandes dimensiones datado en época califal. Al excavarlo, se detectaron varias cimentaciones previas que definían una serie de espacios. Las

6. Como complejos agropecuarios (MOLINA, 2007), baños (COSTA, 2008; CLAPÉS, 2012; COBO, 2018; HUECAS, 2018), mezquitas (COBO, 2018; GONZÁLEZ y COBO, 2019) o almacenes (CLAPÉS, 2014-2015). 


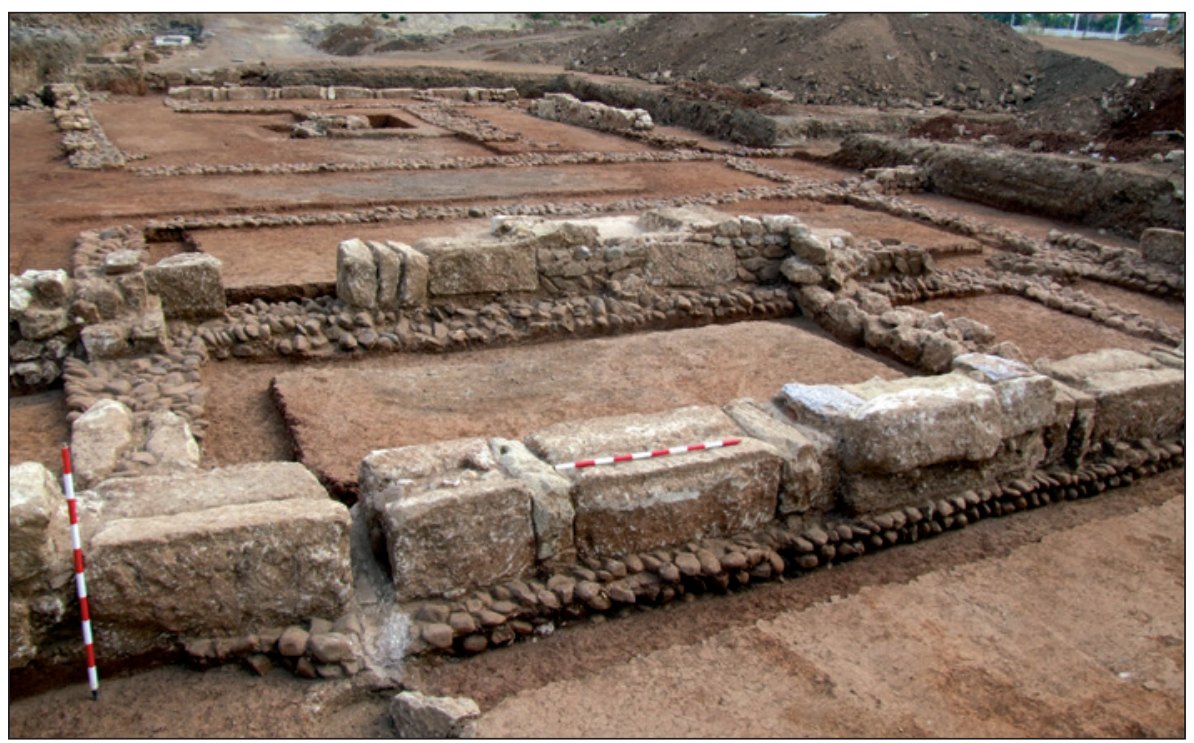

2. Panorámica desde el sur de la edificación emiral.

características de sus muros y el material cerámico recuperado presentan similitudes con los hallados en el arrabal meridional. Estas estructuras se amortizaron durante el califato, llegando incluso a emplearse como primeras hiladas de cimentación de los nuevos muros (CLAPÉS, 2014-2015: p. 229). Por último, en una reciente excavación realizada inmediatamente al oeste del edificio que presentamos a continuación, se excavó otra construcción delimitada por potentes muros que posteriormente fue transformada durante época califal, cuya funcionalidad es difícil de discernir dado el estado de conservación que presenta (COBO, 2018).

Este recorrido nos permite constatar que este sector comenzó a configurarse ya en época emiral, mediante una serie de construcciones que, aunque se conocen hoy de forma muy fragmentada influyeron de forma determinante en el arrabal posterior, desarrollado a partir de las primeras décadas del $\mathbf{S}$. $X$.

\section{LAS FASES DE OCUPACIÓN DEL TERRENO EN ÉPOCA ISLÁMICA (S. IX-S. XI)}

El terreno donde se efectuó la Intervención Arqueológica que nos ocupa se emplaza al norte del Plan Parcial previamente citado. Se realizaron dos campañas de excavación: una primera, entre 2015 y 2016, que consistió en la documentación del arrabal califal; y una segunda, en el año 2017, en la que se detectaron y posteriormente se excavaron las estructuras emirales. No se hallaron fases anteriores al periodo omeya, por lo que todas las estructuras islámicas se asentaban sobre el estrato natural de arcillas característico en esta zona.

\section{LA ETAPA EMIRAL (S. IX-S. X)}

La excavación de la fosa de saqueo de un muro medianero entre dos viviendas califales permitió detectar una cimentación que difería de las halladas hasta el momento en el arrabal, indicando de esta manera la presencia de una construcción previa (Fig. 2). A través de esta diferencia de fábrica se pudo identificar y exhumar un edificio en la mitad occidental del solar. Se trataba de una construcción de planta rectangular con un marcado desarrollo longitudinal, que presentaba dos núcleos edificados sin continuidad entre ellos (Fig. 3). El núcleo de mayor tamaño se encontraba al norte y se estructuró en torno a un patio (espacio A). En su interior albergaba un pozo de abastecimiento fabricado con grandes ripios, 

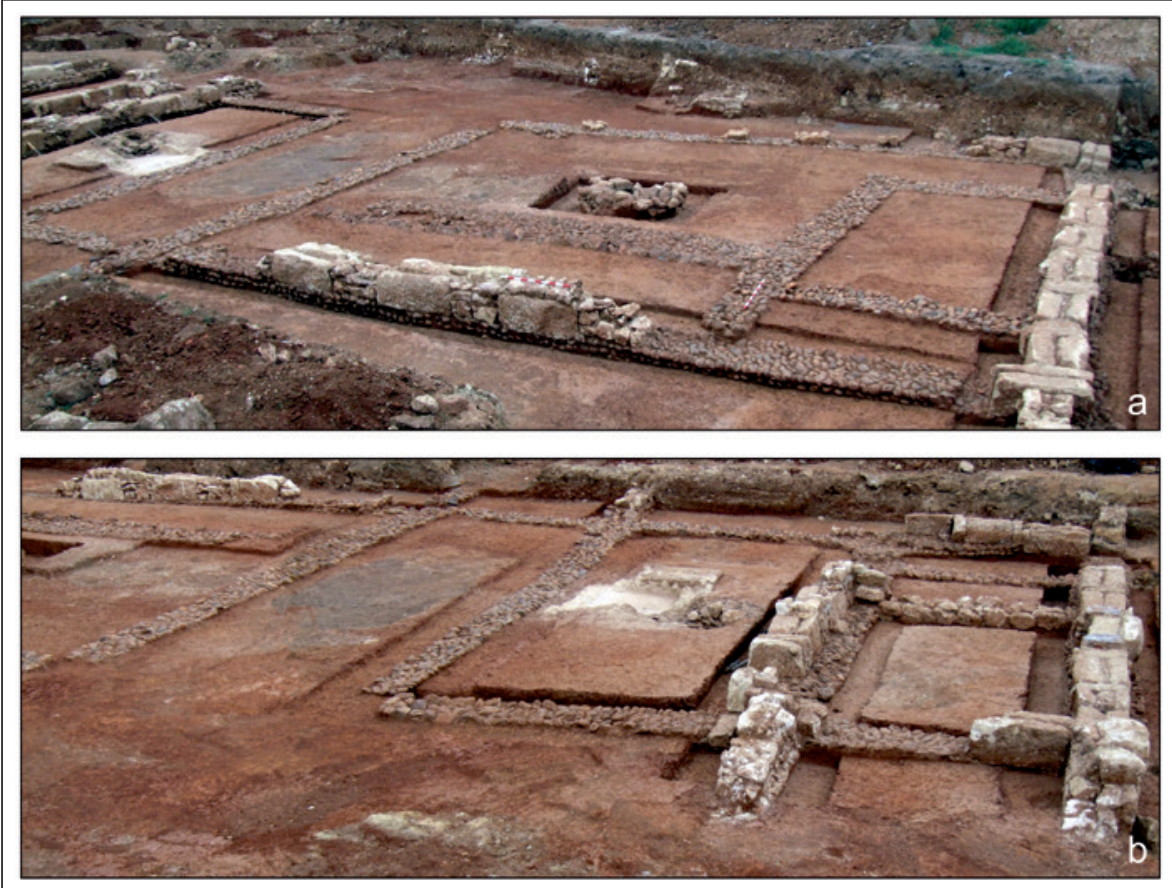

3. Zona norte del edificio emiral, vista desde el este (a), y panorámica desde el oeste de los tres espacios paralelos de la zona meridional (b).

que se dispuso en mitad del cuerpo central, aunque ligeramente desplazado hacia el este. Este patio distribuía tres crujías a su alrededor: una al norte, otra al este y otra al sur. La crujía norte se dividía en tres espacios. El situado al oeste se encontraba completamente abierto al patio (espacio B). Dada su ubicación en uno de los ángulos, podría tratarse de la zona de entrada al edificio por el norte. El espacio C era el de mayores dimensiones y se localizaba en el centro de la crujía. Al este se encontraba el espacio D, que era una pequeña estancia. Por su configuración con respecto al resto de espacios, debía tener acceso desde el espacio C. La crujía este contó con una única sala de grandes dimensiones (espacio E). La crujía sur presentaba otra estancia de gran tamaño sin compartimentar, cuyo cierre oriental no se conservó (espacio F).

El otro núcleo constructivo se localizaba al sur, y estuvo formado por una única sala de planta rectangular (espacio H). La superficie entre ambos núcleos no se halló cerrada por sus extremos este y oeste (espacio G). Contaba con una anchura muy parecida a la de los espacios $\mathrm{F}$ y $\mathrm{H}$, al norte y sur respectivamente.

El análisis de los restos nos lleva a plantear la hipótesis de que los dos núcleos constructivos pudieran haber formado parte de la misma edificación, a pesar de que en algunas zonas los muros hayan desaparecido totalmente (Fig. 4). Este arrasamiento es más claro en la mitad sur, concretamente en los límites oriental y occidental de los espacios F y G. En este último la destrucción era mucho más severa, ya que impedía la conexión física entre los dos núcleos. Sin embargo, dado que ambos se disponían alineados y presentaban características similares, nos llevan a situarlos dentro del mismo conjunto constructivo. Se pudieron determinar los límites de la edificación dado que se conservaron las esquinas de su perímetro. Al exterior de este límite perimetral no se detectaron otros muros que cuenten con la misma tipología edilicia, que permitía identificar este momento constructivo y definir todo el conjunto. La planta resultante presentaba al norte una distribución similar a la de una unidad doméstica, organizada en torno a un patio y con un probable acceso desde el norte, a tra- 


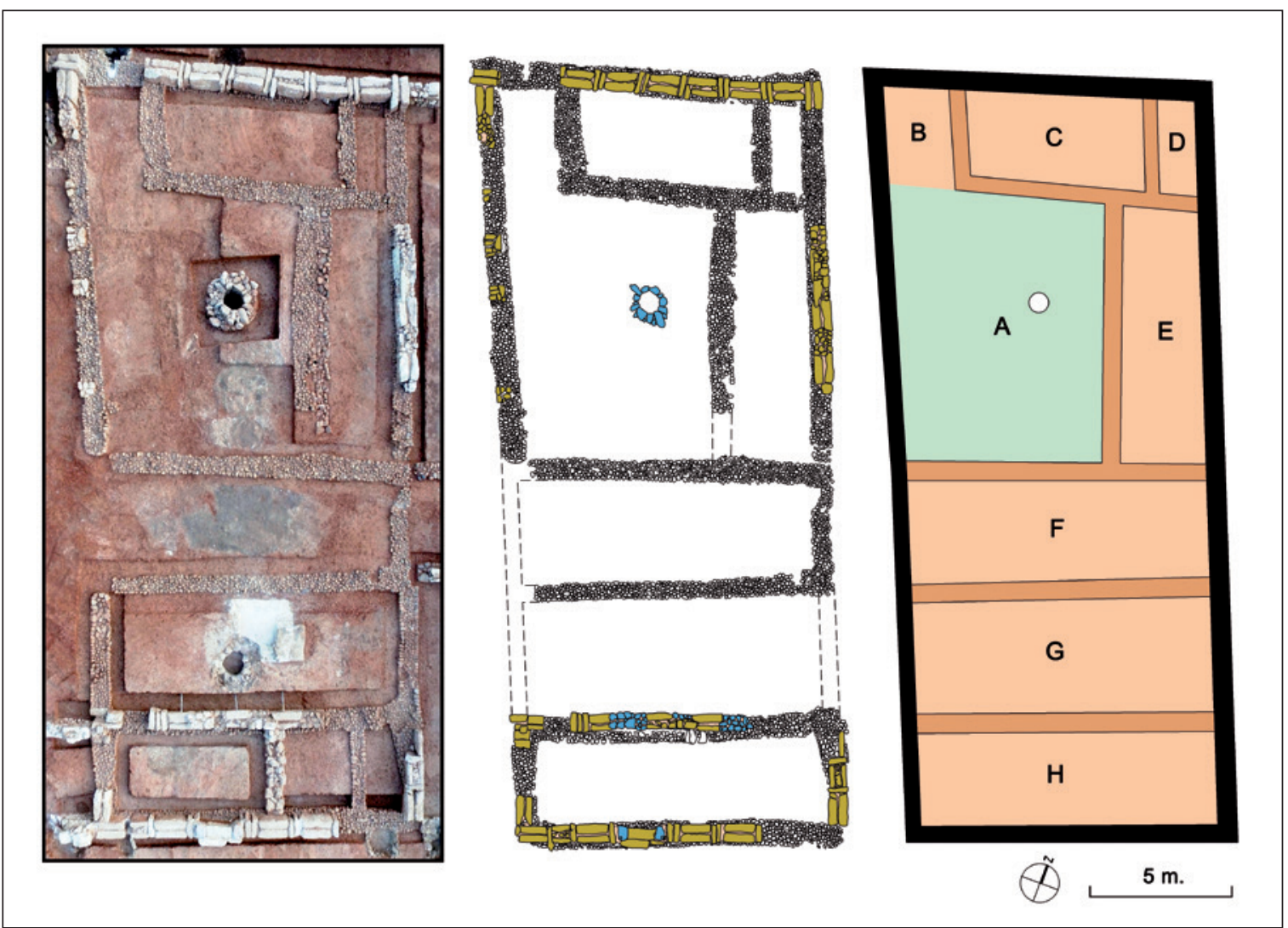

4. Edificio emiral: fotografía aérea, planta con las estructuras pertenecientes a la fase emiral y distribución de espacios constructivos.

vés del espacio B. En la mitad sur se sitúan tres estancias, dispuestas paralelas entre sí y sin indicios de compartimentación interna (espacios F, G y H), de las cuales el espacio F podría haber formado parte del sector septentrional, a modo de crujía sur del patio.

\subsection{Técnicas constructivas}

La edilicia de los muros jugó un papel importante en la identificación de esta construcción. En este sentido, destacan las primeras hiladas de cimentación que, formadas con cantos rodados y mal regularizadas, presentan una anchura de entre 0,75 y 1,00 m (Fig. 5). Para construirlas se realizaron las zanjas de cimentación sobre el terreno natural, ligeramente irregulares, que posteriormente se rellenaron con estos cantos rodados, dando como resultado unas estructuras murarias que en planta se mostraban desalineadas por ambas caras. Los muros perimetrales contienen dos hiladas de cantos rodados generalmente, aunque en algún caso se observan hasta tres. Por su parte, los muros interiores conservan una sola hilada de cantos rodados.

Sobre este primer nivel de cantos rodados, y formando también parte del cimiento, se dispusieron tramos de bloques de sillería que nos han llegado muy fragmentados, y que presentaban dos técnicas constructivas diferentes. Por una parte, se emplearon sillares de calcarenita a soga y tizón ${ }^{7}$, detectada en la fábrica de los muros que delimitan al norte y sur el edificio (Fig. 6a y 6b). Por otra, el resto de muros tenía

\footnotetext{
7. Concretamente dos sogas paralelas, de entre 1,00 y 1,10 m. de longitud, alternadas con dos tizones de menor longitud para no superar el ancho del muro $(0,65-0,76$ m.). El muro meridional presentaba algunas alteraciones en esta fábrica, relacionada con modificaciones posteriores acaecidas en época califal.
} 


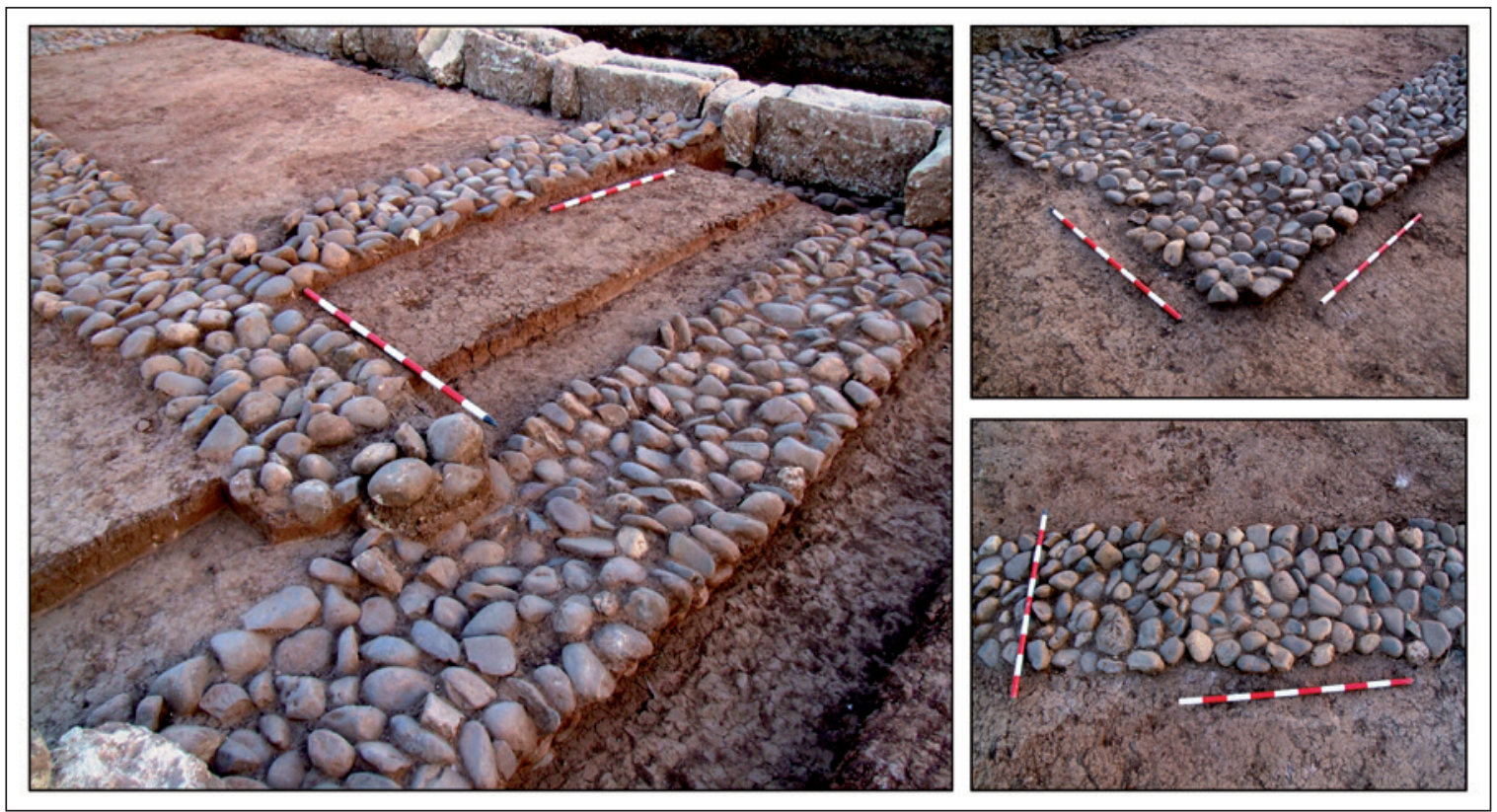

5. Base de los cimientos de época emiral, realizados con cantos rodados.

una edilicia realizada mediante dos sillares de calcarenita paralelos dispuestos a soga, que alternaba con cajas de mampostería. En el muro oriental de la construcción, al este del espacio E, aún permanecían restos de una hilada superior que continuaba con esta misma técnica, pero sus sillares se apoyaban sobre el mampuesto y viceversa, dando lugar a un esquema en damero (Fig. 6c). Esta técnica se ha documentado en tres muros -lados oeste y este del conjunto, y cierre septentrional del espacio $\mathrm{H}-$, aunque hay una ligera modificación en cuanto a los materiales empleados en las cajas de mampostería. En los muros laterales del complejo constructivo se usaron nódulos de calcarenita, mientras que en el muro norte del espacio $\mathrm{H}$ se utilizaron calizas y esquisto (Fig. 6d). Tanto este muro como el cierre oriental del espacio $\mathrm{H}$ presentaban algunos sillares que están asociados a la reforma llevada a cabo en época califal y que, por tanto, rompían el esquema que se ha planteado. No se conservó ningún paramento interior más con la potencia suficiente para documentar su técnica edilicia.

Dado que los muros se conservaban a nivel de cimentación, no se han localizado los pavimentos. La cota de estos probablemente sería muy similar al de las viviendas que amortiza- ban esta construcción. De la misma manera, estos muros tampoco contaban con la potencia suficiente para que fuera posible detectar los vanos, lo que hubiera permitido identificar de forma más precisa la articulación interna del edificio.

\subsection{Aspectos cronológicos}

El momento de construcción del edificio se ha podido establecer a partir de dos indicadores: por un lado, el material cerámico; por otro, la técnica constructiva de los muros. En cuanto al primero, apenas se ha recuperado cerámica de las cimentaciones de los muros. Lo poco con lo que contamos se limita a pequeños trozos que no aportaban una cronología fiable. En su mayoría son fragmentos de cerámica común sin forma alguna, aunque también se encontraron unos pequeños galbos de cerámica vidriada de época emiral, que en Córdoba está presente entre mediados del s. IX y principios del s. X (SALINAS, 2013). El segundo indicador cronológico para este conjunto es la fábrica utilizada en tres de los muros, consistente en el uso de sillares de calcarenita alternados con cajas de mampostería. Esta edilicia mixta se documentó en el alcázar omeya, concretamen- 

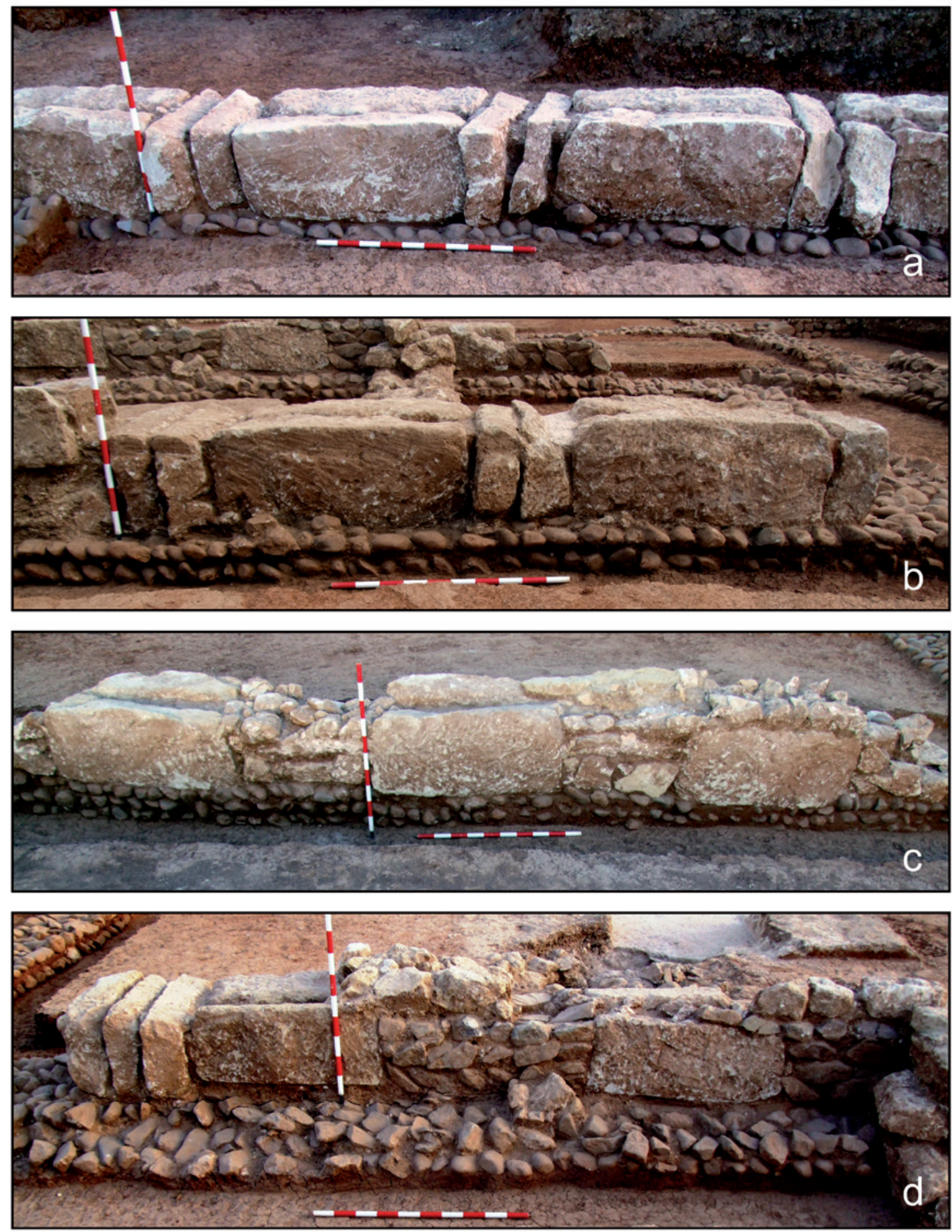

6. Fábricas del edificio emiral: muros perimetrales norte (a), sur (b), este (c) y muro divisor de los espacios $G$ y $H(d)$.

te en el arrecife o malecón que 'Abd al-Rahmān I/ mandó reconstruir en torno a los años 30 del s. IX (MURILLO et alii, 2009-2010: pp. 192-194).
También ha aparecido en otras excavaciones realizadas en la ciudad, como en la mezquita de la Ronda Oeste (GONZÁLEZ, 2016: p. 138- 
139), en el muro identificado como la cerca de la almunia de al-Rușāfa (MURILLO, 2009: p. 461), en estructuras asociadas al rabad Balāt Mugit en los terrenos del Zoológico Municipal (RUIZ et alii, 2008: pp. 174-177), en muros hallados en la zona de El Tablero (CASTILLO y CLAPÉS, 2005), y en otros edificios emplazados en el entorno de nuestra construcción (MOLINA, 2007; COBO, 2018).

Se ha planteado la influencia tardoantigua para esta técnica constructiva de época emiral (LEÓN, 2006: 429; 2018b: p. 2), que está relacionada con el programa edilicio que tuvo lugar a partir del gobierno de 'Abd al-Rahmān II en el s. IX, concretamente con edificios de cierta entidad vinculados con proyectos oficiales (RUIZ et alii, 2008: nota 11). Los contextos cerámicos asociados a esta técnica, cuando se han detectado, remiten en todos los casos al s. IX. Así pues, si tenemos en cuenta tanto la cerámica como la fábrica mixta de algunos de los muros del edificio, se puede enmarcar la cronología de esta construcción entre la mitad del s. IX y los primeros años del s. X.

\subsection{Otras posibles estructuras de época emiral}

Inmediatamente al sur de los restos que hemos analizado, se localizaron varias estructuras susceptibles de formar parte de esta primera fase (Fig. 7a). Se trata de muros con unas cimentaciones similares a las del edificio que acabamos de describir, aunque carentes de una continuidad que haya permitido identificar los posibles límites de una construcción. Uno de estos muros - concretamente, el que servía como fachada meridional de la calle sur del arrabal - presentaba una fábrica muy heterogénea, con un tramo cuyas primeras hiladas de cimentación estaban formadas por cantos rodados, similares a los que hemos analizado, sobre los que apoyaban una hilada de sillarejos. Sobre estos, se disponían sillares a soga y tizón, empleándose en este caso solo un tizón y no dos, como sí ocurría en el edificio situa- do al norte (Fig. 7b). Hacia el tramo oeste de este muro deja de emplearse la base de cantos rodados, y se empiezan a utilizar nódulos y sillarejos de calcarenita. Esta variación de técnica se produce de forma paulatina e irregular, sin que exista un límite claro entre las distintas fábricas que permitan identificar distintos momentos constructivos.

Por último, se excavaron otras dos cimentaciones de cantos rodados, con una anchura que oscila entre los 0,80 y 0,90 m., que sostienen un alzado de sillarejos y mampostería, pero en ningún caso sillares (Fig. 7c y 7d). A pesar de estas similitudes en cuanto a la edilicia, estos muros se disponen de forma aislada, por lo que no se pueden relacionar de forma directa con ninguna edificación concreta previa a las viviendas del s. $X$.

\subsection{Tipología y funcionalidad}

Los límites constatados para la construcción que estamos analizando generan una planta rectangular y alargada. En ella, se observa una zona al norte que se organiza como un ámbito doméstico en torno a un patio. Al sur hay otra zona formada por tres espacios paralelos a modo de naves, quizás empleados como lugares de almacenamiento asociados con la explotación agropecuaria del entorno. La ausencia de niveles de suelo, como consecuencia de la amortización del edificio por las viviendas posteriores, impide una aproximación más exacta a la funcionalidad de sus estancias.

Se trata, por tanto, de una edificación de cierta envergadura con potentes muros. A estos edificios singulares documentados por la arqueología en el entorno de la medina se les ha denominado generalmente como "almunias". Se trata de un repertorio tipológico amplio, que engloba desde las construcciones que cumplen estrictamente con la definición de almunia descrita por García Gómez ${ }^{8}$, cuyo ejemplo más paradigmático es al-Rummaniyya (ARNOLD; CANTO y VALLEJO, 2008; 2018), hasta grandes viviendas

\footnotetext{
8. “Un 'cortijo': una casa de campo, rodeada de un poco o mucho de jardín y de tierras de labor, que servía de residencia ocasional, y era, al mismo tiempo, finca de recreo y explotación" (GARCíA, 1965: p. 334).
} 


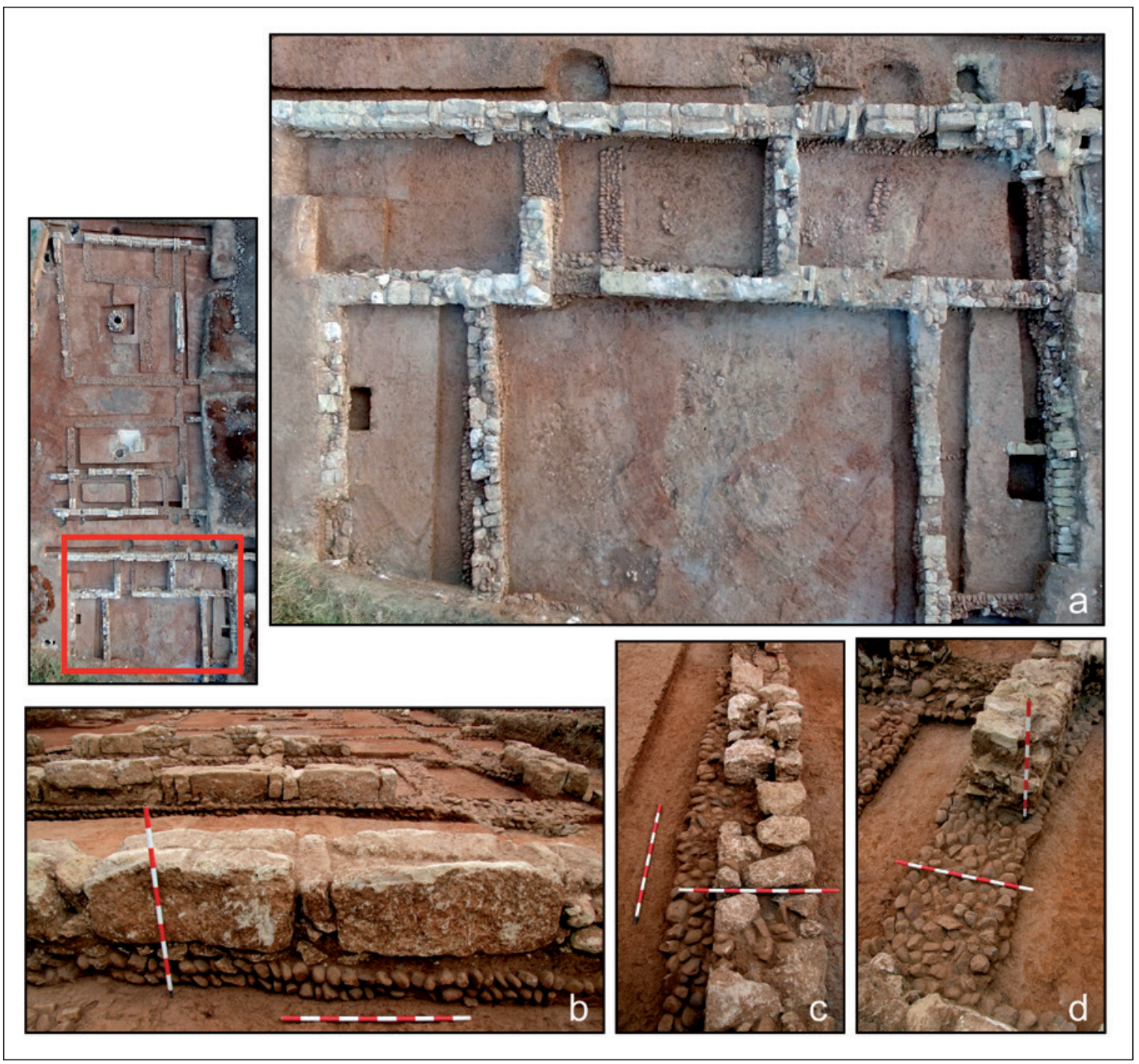

7. Muros y cimentaciones susceptibles de estar asociadas a la primera ocupación islámica, al sur de la edificación emiral.

o palacetes localizados en los arrabales de la ciudad $^{9}$. El área edificada de estas construcciones singulares es similar al modelo de las viviendas que se suele encontrar en los arrabales, aunque con mayor envergadura y monumentalidad que estas, y dotadas con varios patios que presentan esquemas circulatorios principales entre ellos (LÓPEZ, 2013: pp. 255-256). Se han definido cuatro tipos de esquemas para estos edificios en Córdoba: un esquema "básico", ordenado en torno a un patio y rodeado por un muro con contrafuertes; un esquema "tripartito", con un núcleo central y dos laterales que generan una estructura en tres "bandas"; un tercer esquema en que las unidades del tipo uno se yuxtaponen a lo largo de un eje o dos; y por último, las que presentan un sector residencial al norte, con el resto del recinto ocupado por jardines y huertas (MURILLO, 2014: pp. 94-95).

Ninguno de esos esquemas se identifica, $a$ priori, en la edificación que nos ocupa. Al con-

\footnotetext{
9. Como, por ejemplo, los edificios singulares documentados en la zona arqueológica de Cercadilla (FUERTES, 2007) o en el Vial Norte (ARNOLD, 2010) que, por el momento, no están asociados con una almunia.
} 
trario, esta presentaba una planta sencilla y de modestas dimensiones, especialmente si se compara con estas grandes residencias. Si bien sus muros tenían cierta entidad constructiva, carecía de otros elementos representativos, como contrafuertes. No obstante, no podemos descartar que pudiera haberse insertado dentro de una propiedad mayor junto con otros edificios. Ya hemos hecho mención con anterioridad a la presencia de una construcción en la manzana colindante al oeste, que presentaba unas características similares en cuanto a fábrica y cronología (COBO, 2018). Se encontraba, también, al interior de la superficie de terreno definida por las dos calles. Si esta relación se confirmase, estaríamos ante un posible esquema organizativo en torno a un eje que podría identificarse con el tercer tipo descrito más arri$\mathrm{ba}^{10}$. También se ha documentado la presencia de varios edificios independientes más al sur, concretamente en la zona central del Plan Parcial ${ }^{11}$. En consonancia con la información que tenemos actualmente, la construcción emiral que estamos analizando parece asemejarse más a una tipología de carácter doméstico y agropecuario que a edificios de corte palaciego, más complejos en cuanto a su distribución y con un núcleo edificado de carácter netamente aristocrático (MURILLO, 2014: p. 91).

\section{LA TRANSFORMACIÓN CALIFAL (S. X-XI)}

El crecimiento extramuros de la ciudad en época califal generó que en todo este sector se desarrollara el arrabal occidental de la medina, lo que supuso también la amortización de sus construcciones previas. En la parcela que nos ocupa, se edificaron viviendas que se organizaron en tres manzanas en torno a dos calles paralelas, una al norte y otra al sur, orientadas de suroeste a noreste. La interacción entre la primera construcción emiral y el arrabal califal posterior caminaba en dos direcciones: una en la que dicho edificio emiral influyó de forma directa en el nuevo tejido urbano, y otra en la que el arrabal incorporó el área edificada con anterioridad, segregándola y convirtiéndola en viviendas integradas dentro del nuevo barrio (Fig. 8).

\subsection{La adaptación del nuevo arrabal a los condicionantes urbanísticos previos}

Las calles que articulaban las manzanas de casas se disponían a norte y sur de la edificación emiral, manteniendo su misma orientación suroeste-noreste. El muro septentrional y el muro meridional de este edificio previo actuarán como muros de fachada de las calles, que se prolongaron a partir de ellos (Fig. 9). Se puede apreciar un cambio de edilicia en los nuevos tramos de la fachada, realizados con mampostería, a diferencia de los más antiguos de sillería que pertenecían al edificio. El alzado de ambas fábricas se realizó con tapial, lo que favoreció la regularización de toda la fachada. La superficie resultante entre ambas calles generó una manzana de viviendas, cuya anchura coincidía con la longitud de la construcción previa. Esta quedaría integrada en el interior de esta área destinada a casas. Además de esta manzana, ubicada en el centro, se excavaron otras dos, una al norte y otra al sur (Fig. 10).

La manzana se estructuraba en una doble hilera de viviendas, una con acceso desde la calle norte y otra desde la calle sur. Ambas hileras estaban delimitadas entre sí por un muro medianero corrido, paralelo a los muros de fachada de las calles. El trazado de este muro, que marcaba también el eje central de la manzana, coincidía con el muro que separaba los Espacios A y E del Espacio F en la construcción emiral. Así, este paramento se empleó como cimentación sobre la que apoyaba el nuevo

10. A este respecto, se ha considerado que toda almunia contó con uno o más edificios singulares, pero la presencia de un edificio de estas características no tuvo por qué formar parte necesariamente de una almunia (MURILLO, 2014: p. 86).

11. Se trata de la Manzana 2, donde se excavó una construcción emiral con una potente cimentación, que solo conservaba tres espacios. A esa primera edificación, se sumaron otras cinco en época califal (identificadas como una vivienda, una zona de servicio, un espacio doméstico, una cuadra y una casa con establo). Todos estos edificios estaban separados entre sí por un camino central, y se encontraban rodeados por áreas vacías que pudieron haber sido utilizadas como huertas y jardines (MOLINA, 2007). 


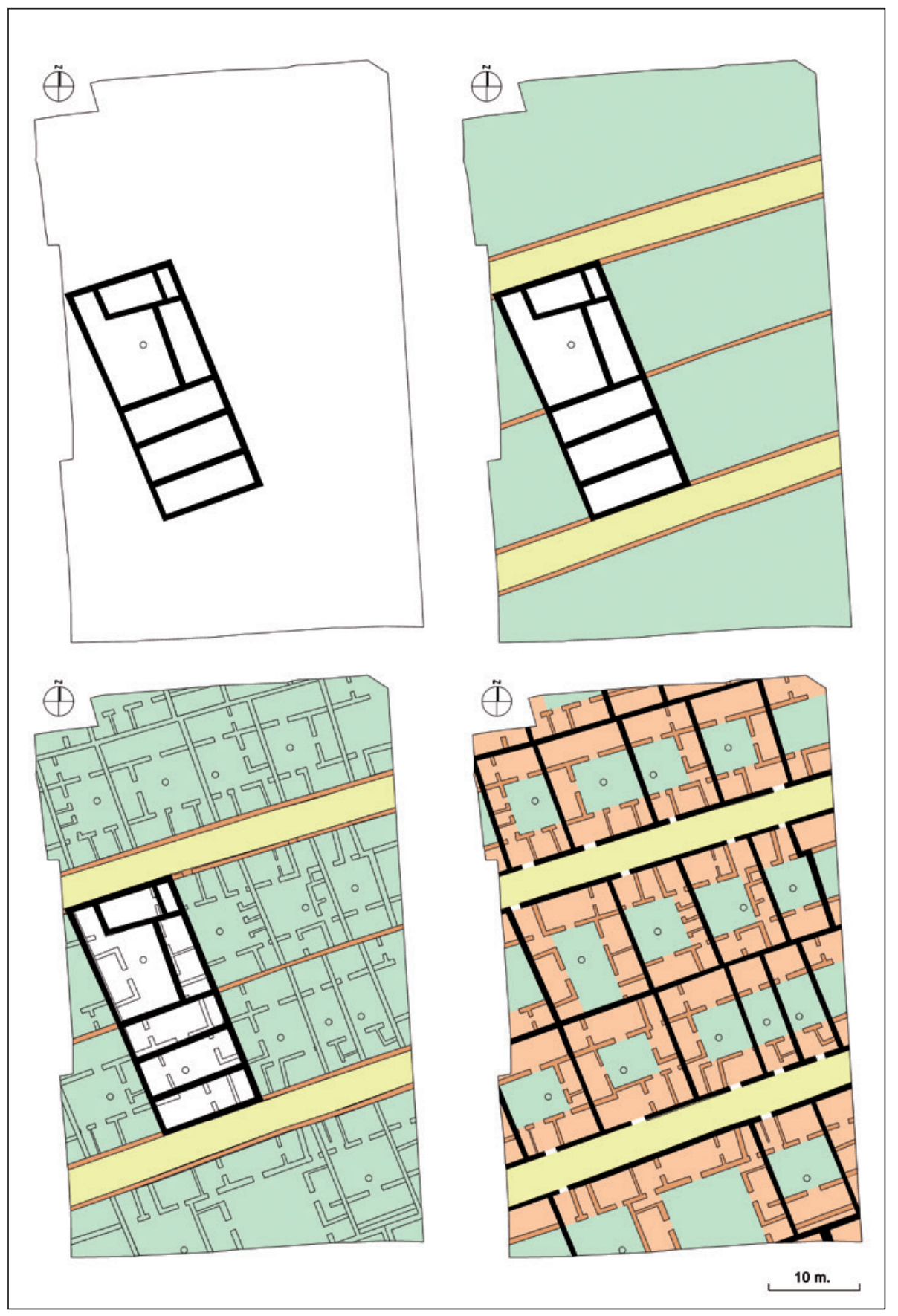

8. Evolución desde la primera fase emiral hasta la construcción del arrabal califal.

muro medianero, contribuyendo también de esta forma a la delimitación de viviendas dentro de la manzana.

Por tanto, los muros norte y sur del edificio emiral, además del muro central, generaron el esquema de la manzana y estable- cieron los límites y las líneas de viviendas. A partir de esta primera división, se levantaron otra serie de muros corridos, también paralelos, que acabarán de determinar la configuración interna de las casas. Un primer muro, más cercano a la calle, delimitaba la crujía de entrada a la vivienda, donde se ubi- 

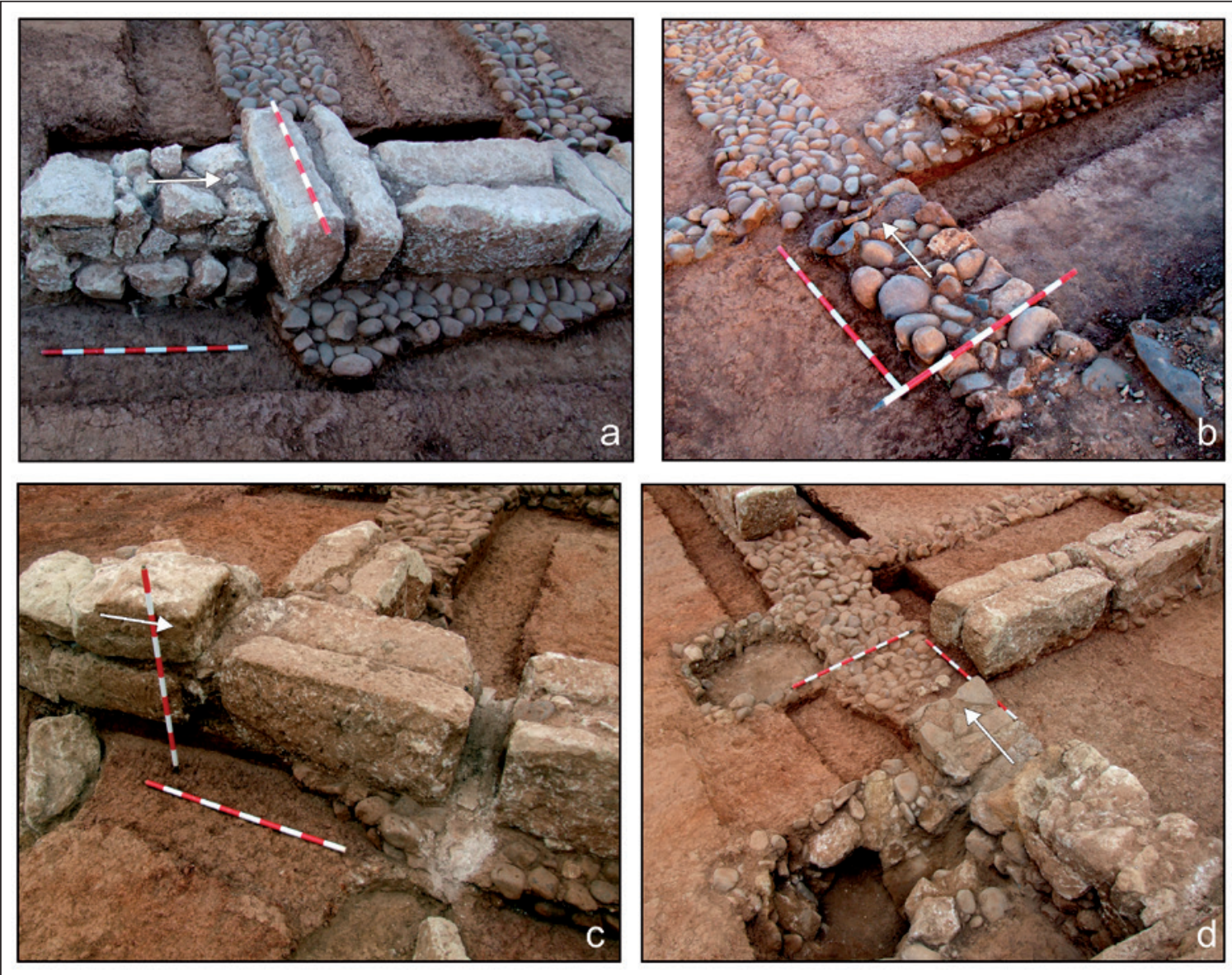

9. Muros de época califal adosándose al edificio previo emiral: esquina noreste (a), lateral oriental (b), esquina suroeste (c) y ángulo sureste (d).

caban el zaguán, la letrina y alguna estancia auxiliar, como una alcoba o un establo. En el siguiente cuerpo se encontraba el patio, que presentaba en uno de sus dos lados una crujía lateral. Por último, otro muro corrido definía la crujía del fondo de la casa, donde se emplazaba el salón que, en algunos casos, contaba también con una alcoba lateral. Posteriormente, se realizó la subdivisión de la manzana en viviendas, que contaron con una superficie similar. Los muros corridos, comunes para todas las viviendas, determinaron que todas ellas tuvieran la misma anchura en sus crujías de acceso, patio y crujía principal. El resto de las compartimentaciones interiores, así como la evolución posterior de cada unidad doméstica, dependió de cada una de las casas. Esta regularidad se vio alterada en las viviendas que ocuparon la superficie del edificio, ya que debieron adaptarse a esta construcción previa.

\subsection{La segregación del edificio emiral en viviendas}

La construcción emiral que analizábamos en el apartado 1 se integró en el resto de la manzana, pasando así a formar parte del nuevo espacio doméstico que se creó en esta zona. Sobre sus restos se levantaron dos viviendas, una al norte y otra al sur. La adaptación al edificio previo influyó en las dimensiones de las casas que, con una mayor anchura que el resto, presentan plantas que tienden al cuadrado y no al rectángulo. Además, la estructuración interna de las mismas también varía, ya que poseen ciertas peculiaridades que las distinguen de las otras viviendas, como veremos a continuación (Fig. 11). 


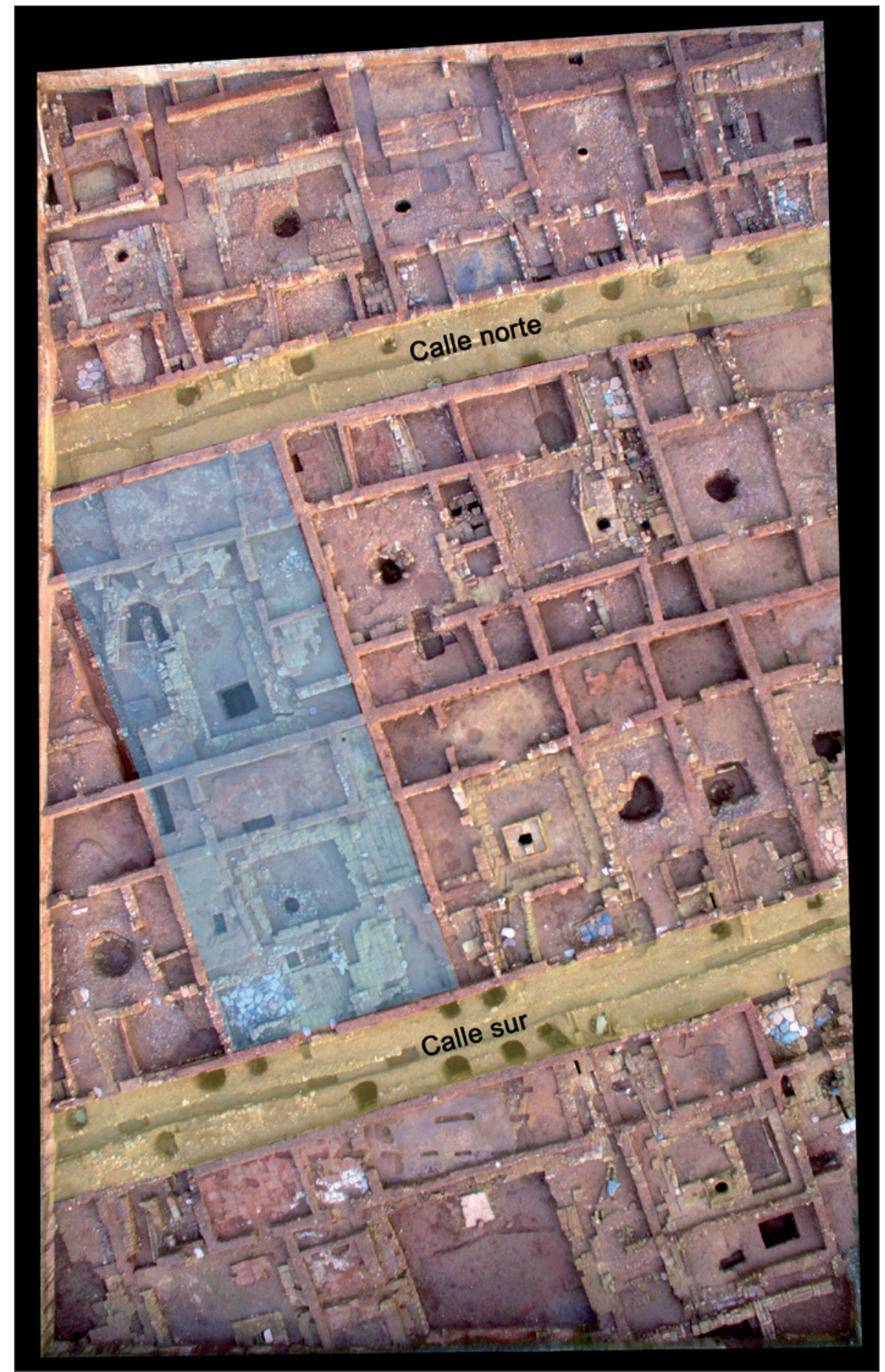

10. Vista aérea del arrabal califal, donde se observan las dos calles que lo ordenan y la superficie que ocupó el edificio emiral.

\subsubsection{La vivienda norte}

Esta casa se ubicó sobre los espacios A, B, C, D y E de la edificación anterior y mantuvo aproximadamente su misma organización, aunque el número de estancias en la que se compartimentó fue mayor. El patio del edificio previo seguía ejerciendo la misma función (espacio 5), pero en este caso se empleó parte de su superficie para construir una crujía al oeste, dando 


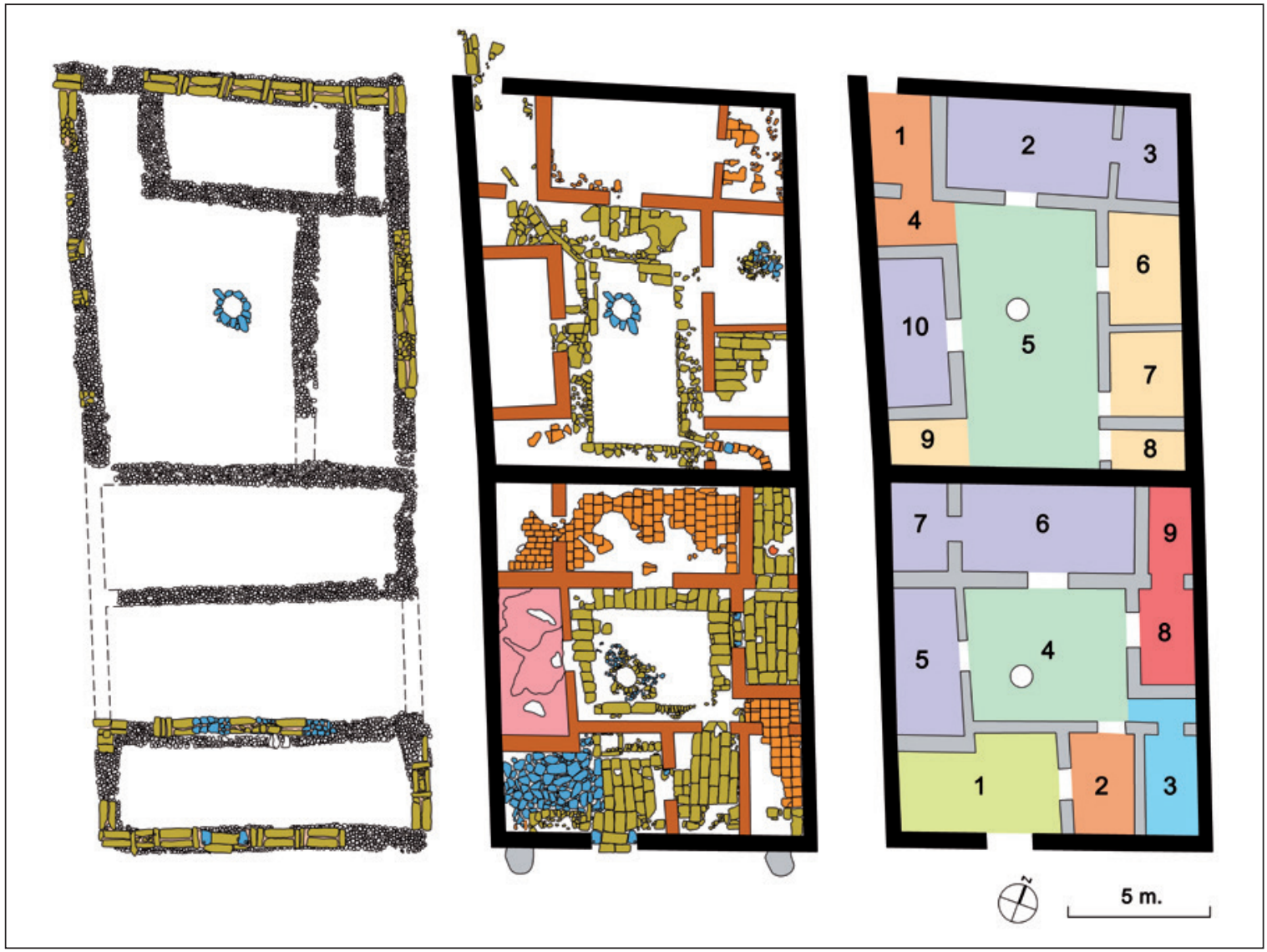

11. La transformación de la construcción emiral en época califal: Planta del edificio previo, planta de las viviendas norte y sur, y división de espacios de estas.

como resultado un espacio abierto más reducido, de planta rectangular. Al este se mantuvo la crujía oriental, aunque la situación del muro que la delimita se modificó ligeramente, ya que se desplazó hacia el este. Sobre el muro original de esta crujía se dispuso el andén perimetral del nuevo patio. La crujía norte se mantuvo delimitada por el mismo muro. El resultado fue la configuración de una casa articulada en torno a un patio central con tres crujías (Fig. 12).

La entrada a esta vivienda se realizaba desde la calle norte, por la misma estancia desde la que se accedía al edificio emiral anterior (espacio 1). Desde esta habitación, que cumplía las funciones de zaguán, se pasaba a un espacio intermedio que generaba un acceso en recodo (espacio 4) y, desde ahí, al patio, núcleo central de la vivienda. Como indicamos anteriormente, su perímetro estuvo recorrido por un andén de losas cuya anchura fue mayor al norte, lado en el que se ubicaron las estancias principales. El pozo del edificio previo se siguió utilizando para abastecer a la nueva vivienda. El agua sobrante del patio se evacuaba a través de una canalización situada junto al andén occidental.

La crujía oeste se compartimentó en dos estancias. La de mayores dimensiones quedó al norte, pudiendo tratarse de una alcoba (espacio 10). Al sur se ubicó la otra, de tamaño más reducido (espacio 9), que no tuvo ningún muro que la aislara del patio, quedando abierta al mismo. Esta estancia estuvo pavimentada con baldosas y pudo estar destinada al almacenamiento.

La crujía este se subdividió también en tres estancias: una al norte, que al interior aún conservaba parte de un pavimento de gravas 

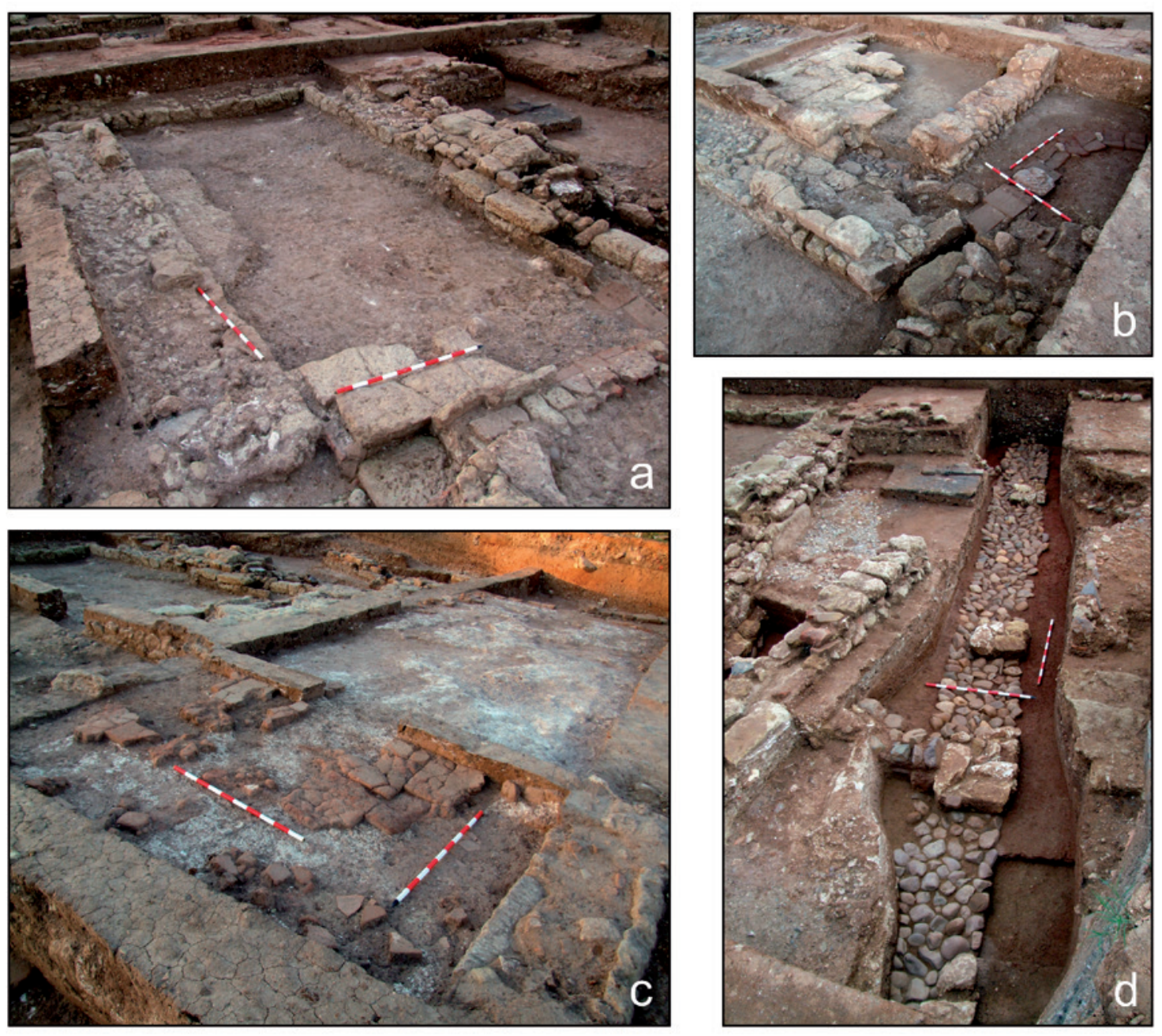

12. Vivienda norte: patio (a), crujía oriental (b) y crujía norte (c). Muro medianero oeste, que permitió la identificación del edificio emiral previo (d).

(espacio 6); otra en la zona central, pavimentada con losas (espacio 7) y, por último, una de pequeñas dimensiones al sur (espacio 8), por la que discurría una conducción que desembocaba en el interior del patio una vez sobrepasado el andén. Esta conducción procedía de la vivienda situada al sur que describimos a continuación, hecho que indica que, a pesar de la subdivisión del edificio emiral anterior, se siguieron manteniendo sus servidumbres de paso, tal y como era habitual en estos casos (VIDAL, 2000: p. 117; HAKIM, 1986: p. 49). Aunque desconocemos la funcionalidad de las estancias de esta crujía oriental, no podemos descartar la posibilidad de que alguno de estos espacios pudiera haber cumplido la función de letrina. Está hipótesis se fundamenta en que no se localizó esta estructura sanitaria en la casa y en que algunas viviendas adyacentes tenían su letrina en esta crujía, tras haberse producido reformas internas.

Finalmente, en la crujía norte se situaron las habitaciones principales de la vivienda. Nos referimos al salón (espacio 2) y a su alcoba lateral (Espacio 3), delimitadas por medio de un estrecho tabique. Estas estancias se situaron sobre los antiguos espacios C y D de la edificación emiral, ocupando una superficie similar.

\subsubsection{La vivienda sur}

La casa meridional se asentó sobre los espacios F, G y H del antiguo edificio emiral. Los 

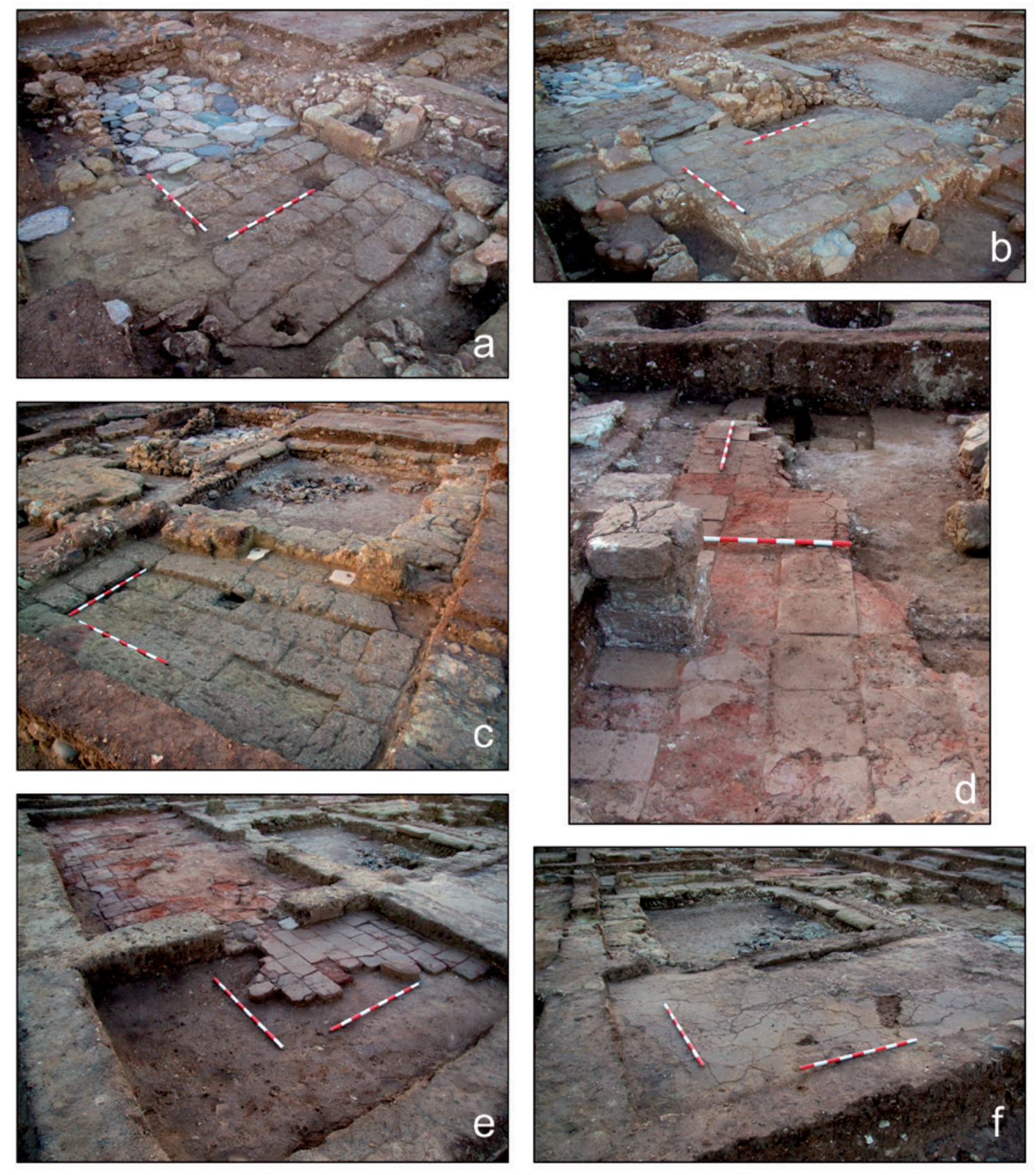

13. Vivienda sur: establo (a), zaguán (b), espacio 16 con el patio al fondo (c), letrina (d), crujía septentrional (e) y alcoba oeste (f).

muros que delimitaban estos tres espacios marcan ahora, a grandes rasgos, la superficie de las tres zonas edificadas principales, es decir, la crujía de entrada (espacio H) al área del patio (espacio G), y la crujía del fondo (espacio F). No obstante, únicamente el muro que definía la crujía de entrada se apoyaba direc- tamente sobre el paramento previo, puesto que el muro que limitaba el patio y la crujía del fondo se desplazó ligeramente y varió su orientación para coincidir con el del resto de viviendas. Esta casa presentaba un patio central y cuatro crujías alrededor, la única de este tipo documentada en el arrabal (Fig. 13). 
La entrada se realizaba desde la calle sur a través de una estancia que cumplía la función de establo y que presentaba dos zonas diferenciadas (espacio 1). La primera de ellas, al oeste, estuvo pavimentada con losas de caliza, empleadas habitualmente en este tipo de salas destinadas a animales. Poseía una estructura adosada al muro de fachada a modo de pesebre, así como un sumidero de evacuación de los deshechos hacia un pozo negro situado en la calle. Al este se encontraba la otra zona, más cercana a la entrada desde la calle, que estuvo pavimentada con losas de calcarenita. Esta parte también contó con estructuras adosadas, concretamente en el muro del fondo que limitaba con el patio. No se ha hallado ningún muro que defina estos dos ámbitos, por lo que pudo haber estado compartimentado por un elemento portante de madera o similar. Tampoco se detectaron evidencias de otro acceso al establo que fuera independiente a la entrada principal de la casa. Desde el espacio 1 se penetraba, a través de un vano situado al este, a una estancia intermedia entre el establo y el patio (espacio 2) que funcionó como zaguán, generando una entrada en recodo hacia el patio. Esta misma solución se documentó en otra de las viviendas, en la que se accedía directamente al establo y, desde este, a una estancia que haría de transición con el patio y que separaba la zona destinada a animales del ámbito estrictamente doméstico. La última de las salas de esta crujía de fachada es la letrina (espacio 3), que estaba situada en la esquina suroriental de la casa y tenía acceso acodado desde el patio. Vertía los residuos hacia un pozo negro que se ubicaba en la calle.

El patio ocupaba la zona central de la casa (espacio 4), con una planta prácticamente cuadrada y con unas dimensiones más modestas que las del resto de las viviendas excavadas, ya que las cuatro crujías le restaban superficie. En el patio se encontraba el pozo de abastecimiento y contaba con un andén perimetral de losas de calcarenita. La crujía occidental albergaba una alcoba con un suelo de mortero de cal (espacio 5). En la crujía septentrional se encontraba el salón (espacio 6), con una alcoba lateral al oeste (espacio 7). Ambos espacios presentaban un suelo de baldosas.

Por último, esta casa poseyó dos estancias relacionadas entre sí en la zona nororiental. Desde el patio se entraba a las primeras de estas salas (espacio 8), que presentaba un pavimento de losas más elevadas en su perímetro, con la zona central ligeramente deprimida. Desde aquí partía una conducción que evacuaba en el patio. El espacio 8 conecta con el espacio 9 a través de un vano sin cierre, cuya superficie ocupaba parte de la crujía norte. Estaba pavimentada también con losas y presentaba en el centro un pequeño rebaje circular que contenía una torta de arcilla, endurecida por la acción del calor. Estas dos habitaciones podrían estar relacionadas con una zona de baño o de aseo, menos compleja que las que se han documentado en otras viviendas del arrabal occidental, que contaron con hipocausto o piletas $^{12}$.

\section{REFLEXIONES FINALES}

En nuestra opinión, la influencia de la primera edificación emiral en la configuración del arrabal califal posterior constituye el hecho más interesante del ejemplo que hemos analizado. A pesar de que ha quedado evidenciado cómo este sector se ocupó en el s. IX, aún quedan algunas cuestiones por resolver, como cuál fue la ordenación primigenia de este ámbito suburbano, la funcionalidad de la edificación emiral, o si esta pudo haberse adscrito a una propiedad más amplia. Estos interrogantes se encuentran relacionados entre sí, pues habría que establecer si la construcción emiral se erigió sobre una red viaria que ya existía -y cuyo trazado se mantuvo en uso durante época califal- o si, por el contrario, esta primera edificación condicionó el trazado de las vías posteriores, que se adaptaron de forma regular a su orientación.

12. En el entorno se han excavado varios de estos baños de carácter privado asociados a viviendas, como en la Manzana 1 (VAZQUEZ, 2016: pp. 303 y 306), en la Manzana 14 (CLAPÉS, 2013) y más recientemente en la Manzana 5 (COBO, 2018). 
Resulta complejo asociar de forma inequívoca el edificio emiral a otras construcciones halladas en el entorno, máxime cuando estas no presentaban conexión ni continuidad espacial entre ellas. No obstante, contamos con algunas estructuras que permiten plantear la hipótesis de que el citado edificio hubiese formado parte de un recinto de más envergadura. Como hemos apuntado más arriba, en la manzana situada al sur del mismo se documentaron varias cimentaciones que pudieron haber pertenecido también a esta primera fase de ocupación. Estos muros podrían adscribirse a otra construcción, cuya planta no pudo identificarse porque habría desaparecido prácticamente con la implantación de las viviendas califales. En la misma línea se encontró el edificio detectado en la parcela adyacente, al oeste, que quizás correspondió al mismo conjunto. Si así fuera, la presencia de varias edificaciones, aunque exentas y aisladas entre sí, habría influido en la orientación y en el trazado del viario posterior, ya que el edificio emiral contó con unas dimensiones modestas en comparación con el gran desarrollo que posteriormente tuvieron las calles del $\mathrm{s}$. $X$, que se prolongan decenas de metros a uno y otro lado del mismo (Fig. 14).

Otra de las hipótesis es que los ejes viarios ya se encontraran definidos con anterioridad a la construcción del edificio emiral, fruto de una organización previa asociada a la explotación agraria de todo este sector. En este sentido, se ha estudiado cómo en la ciudad islámica la ordenación del trabajo agrícola demandó formas geométricas y limitadas, sobre las que se fueron disponiendo de forma progresiva espacios urbanos adaptados a esa estructuración prexistente, originándose un parcelario más o menos disperso (NAVARRO y JIMÉNEZ, 2004: p. 239). En el caso de Córdoba, contamos con algunos indicios al respecto que pueden ayudar a definir esta línea de investigación. La ocupación del perímetro suburbano de la capital omeya requirió también de la ordenación de las áreas agrícolas circundantes. Esto se logró, principalmente, a través de la construcción de almunias que se encargaban de explotar el territorio y de surtir de productos básicos de consumo a la población (LEÓN, 2018a: p.135-136). De esta manera, surgieron pequeños núcleos con unidades domésticas y productivas en un paisaje dominado por huertas y tierras de labor, que progresivamente se fue urbanizando y perdiendo su carácter productivo (MURILLO et alii, 2010: p. 543). La adaptación a esa ordenación agrícola previa podría haber influido en la regularidad del tejido suburbano de los arrabales cordobeses, como se ha planteado recientemente para la Ronda Oeste de Córdoba (CAMACHO, 2018: pp. 46-50).

Con todo, esta propuesta no ha podido ser confirmada por el momento para el sector que nos ocupa, ya que carecemos de evidencias materiales tales como pozos o conducciones que apuntasen a la irrigación y articulación de un posible espacio agrícola anterior. Las estructuras hidráulicas documentadas en las dos calles excavadas se constituyeron en el mismo momento en el que se creó el barrio de viviendas, dentro de un sistema de evacuación jerarquizado que tenía su origen en el patio de las casas, desde donde se recogía el agua sobrante y se transportaba, por medio de canalizaciones, hasta la atarjea central de la calle ${ }^{13}$.

Con independencia de que las calles se crearan a partir de la primera ocupación en el s. IX o de que fueran el fruto de una ordenación viaria implantada a partir de un espacio agrario preexistente, no cabe duda de que el arrabal califal se construyó teniendo en cuenta esos condicionantes previos. La constitución de la nueva urbanización del $\mathrm{s}$. $X$ se realizó en un mismo momento, es decir, se trató de una auténtica "promoción inmobiliaria"14. De esta forma, se erigieron los muros de fachada y unos muros divisorios interiores corridos comunes a

13. El sistema hidráulico de los arrabales cordobeses ha sido estudiado por Belén Vázquez en diversas publicaciones. Concretamente el de este sector se puede consultar en VAZQUEZ, 2013.

14. Este término ha sido empleado con anterioridad por otros autores (MURILLO; CASAL y CASTRO, 2004: p. 271; MURILLO et alii, 2010: p. 546), a partir de la información que aportaban las excavaciones en los arrabales y, a pesar de tratarse de un anacronismo, refleja adecuadamente la planificación y estandarización de muchos de estos sectores domésticos. 

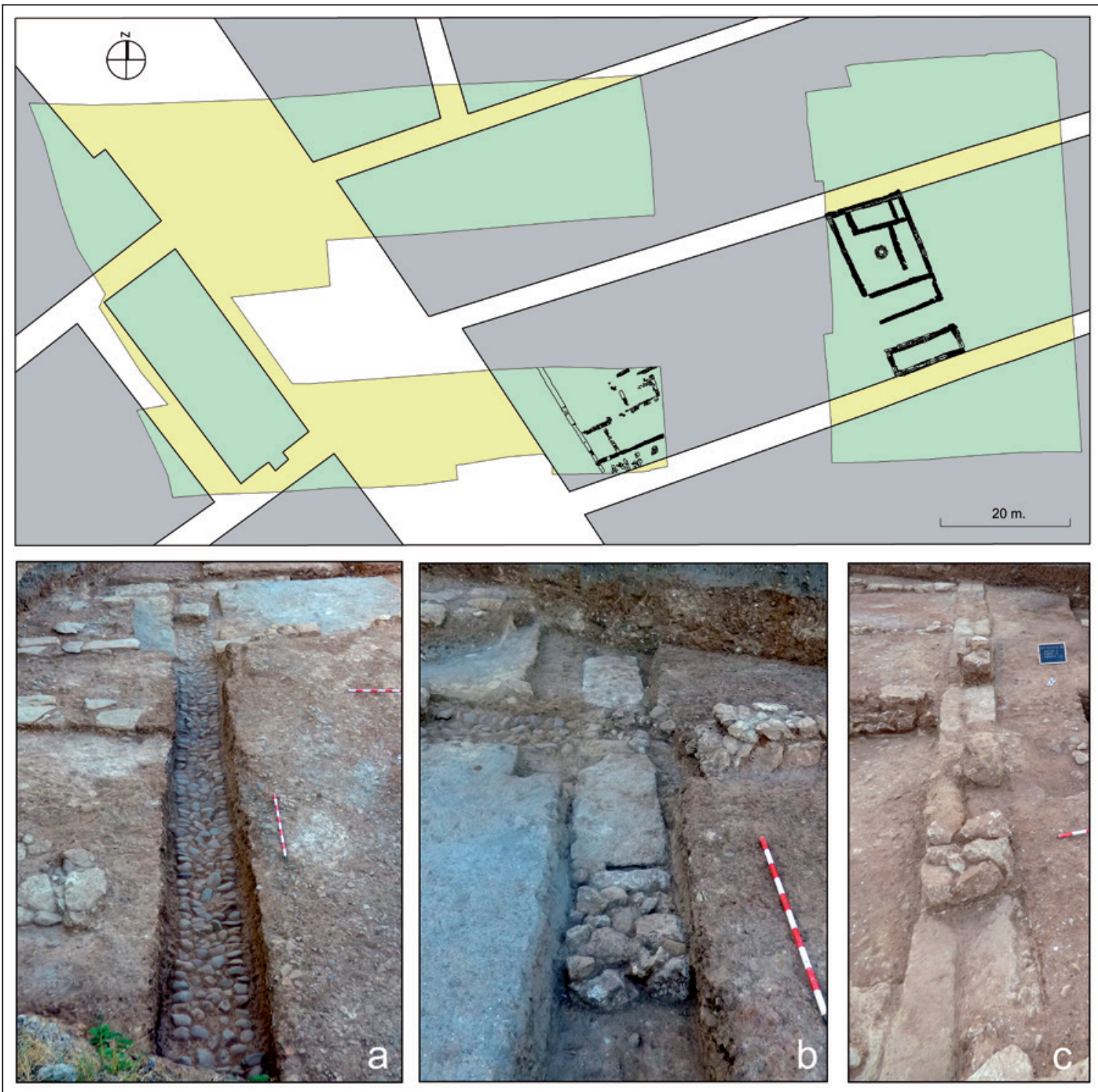

14. Esquematización de la trama urbana de época califal, con la ubicación de los edificios emirales de nuestra parcela y la adyacente. En esta última también se documentaron tanto cimientos de cantos rodados (a) como muros de fábrica mixta (b y c). Ambas construcciones pudieron formar parte del mismo conjunto (fotografías: $M$. Cobo).

todas las viviendas, y posteriormente se determinó la superficie asignada a cada casa. Otro elemento que pone de manifiesto esta planificación es el sistema hidráulico de evacuación, de similares características en todas las casas, realizado mediante canalizaciones talladas en bloques de calcarenita que vertían a la atarjea central de la calle ${ }^{15}$. Por tanto, la existencia de una planificación es incuestionable, aunque determinar quién fue su promotor implica más dificultad ${ }^{16}$. Según las fuentes escritas, las élites cordobesas construyeron edificios que dotaron a la comunidad de los servicios necesarios en los nuevos barrios (MURILLO; CASAL 15. Esta red hidráulica continúa el mismo patrón que la que se documentó en la parcela adyacente al este, donde se advirtió en su mo-
mento esta uniformidad constructiva (VAZQUEZ, 2013: P. 39-40).

16. Este es un tema recurrente que ha sido tratado en varias publicaciones (ACIÉN y VALLEJO, 1998; MURILLO et alii, 2010). 
y CASTRO, 2004: p. 271). En esta misma línea, tampoco debemos perder de vista el relevante papel que jugaron los propietarios de las explotaciones agropecuarias del entorno de la ciudad, ya que la parcelación de sus terrenos para destinarlos a viviendas les debió generar grandes beneficios (LEÓN, 2018a: pp. 144-145).

En definitiva, a través de este recorrido ha quedado de manifiesto cómo el papel de la arqueología es fundamental para entender la islamización del territorio suburbano de Córdoba. Los arrabales califales desdibujaron en gran medida el paisaje previo, pero a pesar de las limitaciones ya mencionadas, contamos con las herramientas necesarias para identificar las primeras ocupaciones que tuvieron lugar durante el emirato. Esta información nos permite discernir, todavía parcialmente, cómo se organizaba el territorio sobre el que posteriormente se establecieron los arrabales y cuál fue el desarrollo evolutivo de los mismos hasta su abandono a principios del s. XI. El caso que hemos presentado aquí es una muestra más de ello, ya que se inserta en un sector que, por sus características y conservación, es un magnífico laboratorio para abordar el estudio del urbanismo andalusí y, por consiguiente, progresar en el conocimiento de la ciudad islámica.

\section{BIBLIOGRAFÍA}

Acién, M.; Vallejo, A. (1998): "Urbanismo y Estado islámico: de Corduba a Qurțuba-Madinat al-Zahrā". Genèse de la ville islamique en al-Andalus et au Maghreb occidental. Madrid, pp. 107-136.

Arnold, F. (2008): "El edificio singular del Vial Norte del Plan Parcial RENFE. Estudio arquitectónico". Anejos de Anales de Arqueología Cordobesa $n^{\circ}$ 2. Córdoba, pp. 247 274.

Arnold, F.; Canto, A.; Vallejo, A. (2008): "La almunia de al-Rummaniyya. Resultado de una documentación arquitectónica". Cuadernos de Madinat al-Zahra n 6. Córdoba, pp. 181-204.

Arnold, F.; Canto, A.; Vallejo, A. (2018): "Investigación en la almunia de al-Rummaniyya (Córdoba) 2006-2014". Almunias. Las fincas de las élites en el Occidente islámico: poder, solaz y producción. Granada, 47-54.

Bermúdez, J. M. (1993): "La trama viaria propia de Madinat al-Zahra y su integración con la de Córdoba". Anales de arqueología cordobesa $n^{0} 4$. Córdoba, pp. 259-294.
Camacho, C. (2018): "Evolución del parcelario doméstico y su interacción con la trama urbana: el caso de los arrabales califales de Córdoba". Arqueología y Territorio Medieval n²25, Jaén, pp. 29-65.

Casal, M ${ }^{a}$ T. (2008): "Características generales del urbanismo cordobés de la primera etapa emiral: El Arrabal de Saqunda". Anejos de Anales de Arqueología Cordobesa $\mathrm{n}^{\circ}$ 1. Córdoba, pp. 109-134.

Casal, Ma T.; Castro, E.; López, R.; Salinas, E. (2005): "Aproximación al estudio de la cerámica emiral del arrabal de Šaqunda (Qurtuba, Córdoba)". Arqueología y Territorio Medieval n 12.2. Jaén, pp. 189-235.

Castillo, F.; Clapés, R. (2015): "Seguimiento Arqueológico en C/ Marino Alcalá Galiano n³ 3 de Córdoba”. Informe administrativo depositado en la Delegación de Cultura de Córdoba (inédito). Córdoba.

Castro, E. (2010): "El arrabal de Cercadilla". El Anfiteatro romano de Córdoba y su entorno urbano. Monografías de Arqueología Cordobesa n 19, vol. II, Córdoba, pp. 615621.

Cepillo, J.; Barea, V. (2017): "Actividad Arqueológica Preventiva en la Parcela 12 B del Plan Parcial 07". Anuario Arqueológico de Andalucía 2008, vol. Córdoba. Sevilla, pp. 1277-1287.

Clapés, R. (2013): "Un baño privado en el arrabal occidental de Madinat Qurtuba". Arqueología y Territorio Medieval n²0. Jaén, pp. 97-128.

Clapés, R. (2014-2015): "La actividad comercial de Córdoba en época califal a través de un edificio hallado en el arrabal de poniente". Anales de Arqueología Cordobesa $n^{\circ}$ 25-26. Córdoba, pp. 225-254.

Cobo, M. (2018): "Memoria Preliminar de la Actividad Arqueológica Preventiva en la Manzana 5 del Plan Parcial 0-7". Informe administrativo depositado en la Delegación de Cultura de Córdoba (inédito). Córdoba.

Costa, M. (2008): "Informe-Memoria. Actividad Arqueológica Preventiva en la M1 P.P. 0-7 de Córdoba”. Informe administrativo depositado en la Delegación de Cultura de Córdoba (inédito). Córdoba.

Criado, A. J. (2007): "Informe-Memoria de la Actividad Arqueológica Preventiva en Manzana 03 del Plan Parcial 07 (Córdoba)". Informe administrativo depositado en la Delegación de Cultura de Córdoba (inédito). Córdoba.

Fuertes, M ${ }^{a}$ C. (2007): "El sector nororiental del arrabal califal del yacimiento de Cercadilla: análisis urbanístico y arquitectónico". Arqueología y Territorio Medieval nº 14. Jaén, pp. 49-68.

García, E. (1965): "Notas sobre la topografía cordobesa en 'Anales palatinos del califa de Córdoba Al-Hakam II, por Isa Razi". Al-Andalus n³ 30, vol. 2. Madrid, pp. 319-379.

González, C. (2016): "Las mezquitas de la Córdoba islámica. Concepto, tipología y función urbana”. Tesis doctoral. Universidad de Córdoba.

González, C.; Cobo, M. (2019): "The use of water in religious spaces in al-Andalus: new archaeological eviden- 
ce from Madīnat Qurtuba's suburbs", en REKLAITYTE, I. (coord.): Water in the Medieval Hispanic Society: Economic, Social and Religious Implications. En prensa.

Hakim, B. S. (1986): Arabic-Islamic Cities. Londres.

Huecas, J. M. (2018): "Informe-Memoria Actividad Arqueológica Preventiva en Parcela 13D Plan Parcial O-7 (Córdoba)". Informe administrativo depositado en la Delegación de Cultura de Córdoba. Córdoba.

León, A. (2006): "Pervivencias de elementos clásicos en la Qurtuba islámica”. El concepto de lo provincial en el mundo antiguo. Vol. II. Córdoba, pp. 409-438.

León, A. (2018a): "El urbanismo de Córdoba andalusí. Reflexiones para una lectura arqueológica de la ciudad islámica medieval". Post-Classical Archaeologies nº 8. Padova, pp. 117-164

León, A. (2018b): "Técnicas constructivas mixtas en piedra en la Córdoba omeya”. Arqueología de la arquitectura $n^{0}$ 15, e078. Madrid.

León, A.; Casal, Mª T. (2010): "Los cementerios de Madinat Qurtuba". El Anfiteatro romano de Córdoba y su entorno urbano. Monografías de Arqueología Cordobesa n 19 , vol. II. Córdoba, pp. 651-684.

Liébana, J. L. (2008): "Actividad Arqueológica Preventiva en la parcela M.15 del PP. O-7 del P.G.O.U de Córdoba". Memoria, Informe administrativo depositado en la Delegación de Cultura de Córdoba (inédito). Córdoba.

López, F. (2013): “La Almunia Cordobesa, entre las fuentes historiográficas y arqueológicas" Onoba n 1 . Huelva, pp. 243-260.

Melchor, E. (1995): Vías romanas de la provincia de Córdoba. Córdoba.

Molina, A. (2007): "Informe y memoria de la Actividad Arqueológica Preventiva de la Manzana 2 del Plan Parcial O-7 de Córdoba". Informe administrativo depositado en la Delegación de Cultura de Córdoba (inédito). Córdoba.

Murillo, J. F. (2009): "La almunia de al-Rusafa en Córdoba". Madrider Mitteilungen nº 50. Mainz, pp. 450-482.

Murillo, J.F. (2013): "Qurtuba califal. Origen y desarrollo de la capital Omeya de al-Andalus". Awraq n 7. Madrid, pp. 81-103.

Murillo, J. F. (2014): "Grandes residencias suburbanas en la Córdoba Omeya. Estado de la cuestión”. Al-Mulk n 12. Córdoba, pp. 85-108.

Murillo, J. F.; Fuertes, M C.; Luna, D. (1999): “Aproximación al análisis de los espacios domésticos en la Córdoba andalusí". Córdoba en la Historia: la construcción de la urbe. Actas del Congreso, Córdoba, pp. 129154.

Murillo, J.F.; Casal, Ma T.; Castro, E. (2004): "Madinat Qurtuba. Aproximación al proceso de formación de la ciudad emiral y califal a partir de la información arqueológica".
Cuadernos de Madīnat al-Zahrā' nº 5. Córdoba, pp. 257290.

Murillo, J. F.; Ruiz, D.; Carmona, S.; León, A.; Rodríguez, Ma C.; León, P. (2009-2010): "Investigaciones Arqueológicas en la Muralla de la Huerta del Alcázar (Córdoba). Anejos de Anales de Arqueología Cordobesa n $^{\circ}$ 2. Córdoba, pp. 183-230.

Murillo, J. F.; León, A.; Castro, E.; Casal, Ma T.; Ortiz, R.; González, A.J. (2010): "La transición de la civitas clásica cristianizada a la madina islámica a través de las transformaciones operadas en las áreas suburbiales". El Anfiteatro romano de Córdoba y su entorno urbano. Monografías de Arqueología Cordobesa n 19, vol. II, Córdoba, pp. 503-547.

Murillo, J. F.; León, A.; López, F. (2018): “La aportación de la arqueología al estudio de las almunias cordobesas: el ejemplo de al-Rusāfa". Almunias. Las fincas de las élites en el occidente islámico: poder, solazy producción. Granada, pp. 27-46.

Murillo, J. F.; León, A.; Vargas, S. (2014): "Patrones de continuidad en la ocupación periurbana de Córdoba entre la Antigüedad tardía y la Edad Media: 1. Los sistemas hidráulicos". Ciudad y Territorio: Transformaciones materiales e ideológicas entre la época clásica y el Altomedievo. Monografías de Arqueología Cordobesa n²0, Córdoba, pp. 137-184.

Navarro, J.; Jiménez, P. (2004): "Evolución del paisaje urbano andalusí. De la medina dispersa a la saturada". Paisaje y naturaleza en Al-Andalus. Granada, pp. 232-267.

Rodríguez, M. (2008): "Informe Preliminar-Memoria Técnica de Actividad Arqueológica Preventiva en la Manzana 4 del Plan Parcial 0-7 de Córdoba". Informe administrativo depositado en la Delegación de Cultura de Córdoba (inédito). Córdoba.

Ruiz, D.; Sánchez, S.; Castro, E.; León, A.; Murillo, J. F. (2008): "La ocupación diacrónica del sector meridional del Ŷănib al-Garbī de Qurţūba (siglos VIII-XIII). Intervenciones arqueológicas realizadas en el Zoológico Municipal de Córdoba. Análisis de conjunto". Anejos de Anales de Arqueología Cordobesa n 1. Córdoba, pp. 163-200.

Salinas, E. (2013): "Cerámica vidriada de época Emiral en Córdoba”. Arqueología y Territorio Medieval n² 20. Jaén, pp. 67-96.

Vázquez, B. (2013): "El agua en la Córdoba andalusí. Los sistemas hidráulicos de un sector del Ŷānib al-Garbī durante el califato Omeya". Arqueología y Territorio Medieval n²0, Jaén, pp. 31-66.

Vázquez, B. (2016): "Arqueología hidráulica en los arrabales occidentales de la Córdoba omeya”. Tesis doctoral. Universidad de Córdoba.

Vidal, F. (2000): "Agua y urbanismo: evacuación de aguas en fatwà-s de al-Andalus y el Norte de África", L'urbanisme dans l'Occident musulman au Moyen Âge. Aspects juridiques, Madrid, pp. 101-123. 
